\title{
In Vitro Evaluation of Reversible and Irreversible Cytochrome P450 Inhibition: Current Status on Methodologies and their Utility for Predicting Drug-Drug Interactions
}

\author{
Stephen Fowler ${ }^{1,3}$ and Hongjian Zhang ${ }^{2}$
}

Received 11 January 2008; accepted 28 April 2008; published online 7 August 2008

\begin{abstract}
It is widely accepted that today's practice of polypharmacy inevitably increases the incidence of drug-drug interactions (DDIs). Serious DDI is a major liability for any new chemical entity (NCE) entering the pharmaceutical market. As such, pharmaceutical companies employ various strategies to avoid problematic compounds for clinical development. A key cause for DDIs is the inhibition of cytochrome P450 enzymes (CYPs) that are responsible for metabolic clearance of many drugs. Screening for inhibition potency of CYPs by NCEs has therefore become a routine practice during the drug discovery stage. However, in order to make proper use of DDI data, an understanding of the strengths and weaknesses of the various experimental systems in current use is required. An illustrated review of experimental practices is presented with discussion of likely future developments. The combination of high quality in vitro data generation and the application of in vivo CYP inhibition modelling approaches should allow more informed decisions to be made in the search for drug molecules with acceptable DDI characteristics.
\end{abstract}

KEY WORDS: cytochrome P450 (CYP); drug interactions; time dependent inhibition.

\section{INTRODUCTION}

Cytochrome P450 enzymes (CYPs) are found in practically all living organisms and have been retained and adapted through evolution due to their unusual ability to oxidise carbon-hydrogen bonds in a regio- and stereo-selective manner. In addition to performing essential biosynthetic and metabolic functions (e.g. structural and signalling molecule biosynthesis, bacterial activation of hydrocarbons for use as carbon sources) animal P450 enzymes also act as important systems for the detoxification of phytochemicals and other xenobiotics. The human CYP enzymes which have evolved to dispose of a wide variety of dietary and environmental toxins now perform the same function in removal of lipophilic small molecule (molecular weight $<1,200 \mathrm{Da}$ ) drug substances from the body.

In the development of a new drug substance, a balance must be reached between the amount of drug which is to be administered and the rate of drug clearance in order to achieve the desired therapeutic plasma or tissue concentration for the required amount of time. As the clearance of

\footnotetext{
$\overline{{ }^{1} \text { Drug Metabolism and Pharmacokinetics, F. Hoffmann La-Roche }}$ Ltd., 4070 Basel, Switzerland.

${ }^{2}$ Drug Metabolism and Pharmacokinetics, Bristol-Myers Squibb Research and Development, Princeton, New Jersey 08543, USA.

${ }^{3}$ To whom correspondence should be addressed. (e-mail: Stephen. fowler@roche.com)
}

most small molecule drug substances is dependent upon CYP enzymes, their inhibition can lead to overexposure and toxicity. Considerable effort is therefore expended in the pharmaceutical industry on optimisation of molecules to avoid pharmacokinetic drug-drug interactions (DDIs) due to CYP inhibition. Although the number of individual CYPs and the number of allelic forms of these enzymes which have been identified is still increasing, the most important enzymes involved in drug metabolism have been known for some time and are described in standard texts (1). To date, it is still most important to identify potent inhibitors of CYP3A4 followed by CYP2C9, CYP2D6, CYP2C19 and CYP1A2. Additionally CYP2C8 and CYP2B6 have been added to the list of enzymes which are recommended for testing in regulatory studies (2).

The aim of this review is to give a basic description of current experimental practices and data extrapolation, with their advantages and disadvantages. There are already many excellent discussions of CYP inhibition and, particularly in the last year, of time-dependent CYP inhibition. Therefore, where the same ground is covered in this review, it is from a more experimental rather than a theoretical point of view.

\section{IN VITRO EVALUATION OF CYP INHIBITION}

\section{In Vitro Methodologies}

A short description of the methods used to measure enzyme activity, and hence enzyme inhibition, is required if 
different experimental systems and screening strategies are to be discussed. As the CYP metabolism reaction cycle consists of substrate binding, enzyme reduction (NADPH oxidation), oxygen reduction, substrate oxidation and product release, there are a number of steps which could be monitored to give an indication of enzyme inhibition by a test substance. In practice however, CYP inhibition measurement is almost always performed by analysing inhibition of substrate metabolism. The different technologies available for measurement of metabolite generation can be categorised as high, medium and low throughput methods (Table I).

In the most frequently applied high throughput method, CYP activity results in oxidation of a pro-fluorescent molecule which then breaks down to give a fluorescent product (usually a hydroxycoumarin, fluorescein or resorufin analogue). These products can then be detected directly using a fluorescence plate reader. This method has the advantage that it is a fast and cost-effective way to perform thousands of $\mathrm{IC}_{50}$ determinations per year $(3,4)$. Measurements may be subject to interference from test inhibitors which either fluoresce or cause fluorescence quenching. However, although these effects are observed, in practice their frequency is usually acceptably low. For example, fluorescence and fluorescence quenching resulted in assay failure rates of between 0.1 and $0.8 \%$ in over 5,000 compounds tested in 2007, accounting for between 12 and $49 \%$ of total failures (Table II).

An analogous high throughput method involves the use of pro-luminescent substrates. Here, CYP activity results in the generation of a luciferin analogue which can be made to luminesce by addition of a development reagent (5). The advantage of luminescence technology is the greatly improved signal to noise ratio which can be achieved, although there are the drawbacks of needing an extra "development" step in the assay process and not being able to read the signal generation in real time. A requirement of both of these high throughput technologies is that recombinantly expressed single enzymes are used, due to insufficient enzyme selectivity of most probe substrates to allow their use with human liver microsomes (HLM), which contain a mixture of many different enzymes.

Technologies which make use of CYP-selective substrates (marketed or formerly marketed drug substances or well characterised biomolecules such as steroids) and can be implemented on a medium throughput basis are the release of radioactivity from a substrate molecule and liquid chromatography-tamdem mass spectrometry (LC-MS)/MS analysis of metabolite generation from unlabelled drug substance molecules. As studies conducted using HLMs and existing drugs as substrates are felt to be closest to the in vivo DDI situation, they are the preferred systems for CYP inhibition screening and the accepted methods for regulatory in vitro DDI studies.

The radiometric methods rely upon release of either tritiated water (following hydroxylation of a labelled $\mathrm{C}-{ }^{3} \mathrm{H}$ moiety and proton exchange with buffer water $(6,7))$ or ${ }^{14} \mathrm{C}$ formaldehyde (following oxidative $\mathrm{O}$ - or $\mathrm{N}$-demethylation of a ${ }^{-14} \mathrm{CH}_{3}$ labelled drug molecule (8)). Unfortunately, both of

Table I. Methods of CYP Inhibition Measurement

\begin{tabular}{|c|c|c|c|}
\hline Method & Comment & Pro & Con \\
\hline $\begin{array}{l}\text { Fluorescence } \\
\text { (high throughput) }\end{array}$ & $\begin{array}{l}\text { Pro-fluorescent substrate } \\
\text { metabolised to give } \\
\text { fluorescent product }\end{array}$ & $\begin{array}{l}\text { Measures actual enzyme activity. } \\
\text { Fast. Sensitive. Cost-effective. } \\
\text { Easy miniaturisation allows } \\
\text { high throughput. Kinetic } \\
\text { mode measurements possible }\end{array}$ & $\begin{array}{l}\text { Recombinant enzymes needed as probes } \\
\text { not CYP selective enough for HLM. } \\
\text { Correlation to HLM assay needed. } \\
\text { Interference from fluorescent or } \\
\text { fluorescence quencher molecules }\end{array}$ \\
\hline $\begin{array}{l}\text { Luminescence } \\
\text { (high throughput) }\end{array}$ & $\begin{array}{l}\text { Pro-luminescent substrate } \\
\text { metabolised to luminescent } \\
\text { product }\end{array}$ & Very sensitive & $\begin{array}{l}\text { Work-up reagent required. High SDS } \\
\text { content of quench reagent not suited } \\
\text { to all automated sample pipettors. } \\
\text { Recombinant enzymes needed for } \\
\text { most enzyme measurements as truly } \\
\text { selective reagents are not yet } \\
\text { developed for all important drug } \\
\text { metabolising CYPs }\end{array}$ \\
\hline $\begin{array}{l}\text { Radiometric } \\
\text { (medium throughput) }\end{array}$ & $\begin{array}{l}\text { Release of radiolabel on } \\
\text { metabolism of substrate } \\
\text { (typically as }{ }^{14} \mathrm{C} \text {-formaldehyde } \\
\text { or as }{ }^{3} \mathrm{H} \text {-water) }\end{array}$ & Fast and accurate. Can use HLM & $\begin{array}{l}\text { Solid phase separation and liquid or } \\
\text { solid scintillation counting required. } \\
\text { Large amount of radiolabelled } \\
\text { substances used. Disposal of } \\
\text { radioactive wastes }\end{array}$ \\
\hline $\begin{array}{l}\text { Radiometric } \\
\text { (low throughput) }\end{array}$ & $\begin{array}{l}\text { Metabolism of labelled substrate } \\
\text { analysed by HPLC-radioflow } \\
\text { or HPLC based fraction } \\
\text { collection/scintillation } \\
\text { counting technologies }\end{array}$ & $\begin{array}{l}\text { Almost free choice of substrate } \\
\text { molecules }\end{array}$ & Analysis slow \\
\hline $\begin{array}{l}\text { LC-MS/MS, } \\
\text { (medium throughput) }\end{array}$ & $\begin{array}{l}\text { Industry standard method for } \\
\text { all high quality/moderate- } \\
\text { high throughput DDI } \\
\text { assessments }\end{array}$ & $\begin{array}{l}\text { Free choice of substrates allows } \\
\text { HLM or recombinant CYP use. } \\
\text { LC-MS/MS analysis technology } \\
\text { sensitive and specific }\end{array}$ & $\begin{array}{l}\text { Significant investment in analytical } \\
\text { equipment required }\end{array}$ \\
\hline
\end{tabular}

SDS sodium dodecyl sulfate, HPLC high-performance liquid chromatography 
Table II. Frequency of $\mathrm{IC}_{50}$ Values Exceeding Aqueous Solubility and Assay Failure Rates for Three Fluorescence-Based CYP Inhibition Screens

\begin{tabular}{|c|c|c|c|c|c|c|c|c|c|c|c|c|c|c|c|}
\hline \multirow[b]{2}{*}{$\mathrm{IC}_{50} /$ Solubility } & \multicolumn{4}{|c|}{ All $\mathrm{IC}_{50}$ values } & \multicolumn{4}{|c|}{$\mathrm{IC}_{50}<50 \mu \mathrm{M}$} & \multicolumn{4}{|c|}{$\mathrm{IC}_{50}>50 \mu \mathrm{M}$} & \multirow[b]{2}{*}{$n^{\mathrm{a}}$} & \multirow{2}{*}{$\begin{array}{l}\text { Percentage Assay } \\
\text { Failure Rate (n) }\end{array}$} & \multirow{2}{*}{$\begin{array}{l}\text { Failure Rate } \\
\text { Due to Fluorescence } \\
\text { or Fluorescence } \\
\text { Quenching (\%) }\end{array}$} \\
\hline & $<1$ & $1-3$ & $3-10$ & $>10$ & $<1$ & $1-3$ & $3-10$ & $>10$ & $<1$ & $1-3$ & $3-10$ & $>10$ & & & \\
\hline CYP2C9 (MFC) & 79.8 & 12.1 & 5.4 & 2.7 & 49.7 & 10.9 & 4.9 & 0.5 & 30.1 & 1.2 & 0.5 & 2.2 & 4,688 & $1.64(5,508)$ & 0.80 \\
\hline CYP2D6 (AMMC) & 71.4 & 11.5 & 10.7 & 6.4 & 49.6 & 9.8 & 9.9 & 2.3 & 21.8 & 1.7 & 0.8 & 4.1 & 4,723 & $0.94(5,402)$ & 0.11 \\
\hline CYP3A4 (DBF) & 68.6 & 12 & 9.6 & 9.8 & 25.6 & 8.6 & 7.9 & 2.6 & 43 & 3.4 & 1.7 & 7.2 & 4,747 & $0.48(5,433)$ & 0.09 \\
\hline
\end{tabular}

${ }^{a}$ Number of molecules where both CYP inhibition and high throughput solubility data were available.

these methods require a solid phase extraction step, for separation of the labelled metabolite from labelled parent material. They also involve extensive use of radiolabelled materials, which is undesirable from both cost and radioactive substance disposal perspectives.

With the development of more sensitive LC-MS/MS machines and the almost ubiquitous use of MS within drug metabolism research centres, LC-MS/MS has become the standard measurement technology for in vitro DDI experiments. The routine analysis of only a few metabolite substances has facilitated the development of high quality, short run-time, LC-MS/MS analysis methods (9). The possibility to pool samples for analysis or to cassette substrates in incubations have further enhanced the throughput of LC-MS/ MS based CYP inhibition assays for early discovery work $(10,11)$. These advances have allowed fast, accurate measurements to be brought to DDI studies in at least a medium throughput, if not yet a high throughput manner.

The 2006 draft guidance from the American Food and Drug Administration about the conduct of DDI investigations is highly prescriptive with a large amount of proposed experimental detail included and helpful (although not exhaustive) tables of substrates and inhibitors in common usage (2). In addition, many authors have described method conditions for the assessment of DDI in vitro, the most thorough of these coming from the lab of Walsky and Obach $(9,12,13)$.

\section{Choice of Substrate Concentrations}

Characterization of CYP inhibition is typically conducted at substrate concentrations where CYP catalysis follows Michaelis-Menten kinetics to avoid complications in data interpretation. Here, the relationship between the rate of catalysis and substrate concentration is consistent with substrate association with a single enzyme binding site and follows hyperbolic substrate-saturation kinetics. A good example of this is the CYP2C19-selective 4'-hydroxylation of $S$-mephenytoin (Fig. 1a), where reaction rate data fit well to the formula $v=v_{\max } *[\mathrm{~S}] /\left(\mathrm{K}_{\mathrm{M}}+[\mathrm{S}]\right)$ over the entire concentration range tested. In contrast midazolam, which exhibits CYP3A4/CYP3A5 selective 1'-hydroxylation by HLMs and is frequently used as a CYP3A substrate for inhibition studies, clearly shows substrate inhibition kinetics (Fig. 1b). To allow straightforward data extrapolation, low (up to $5 \mu \mathrm{M}$, MichaelisMenten kinetics still followed) concentrations of midazolam are therefore used experimentally.
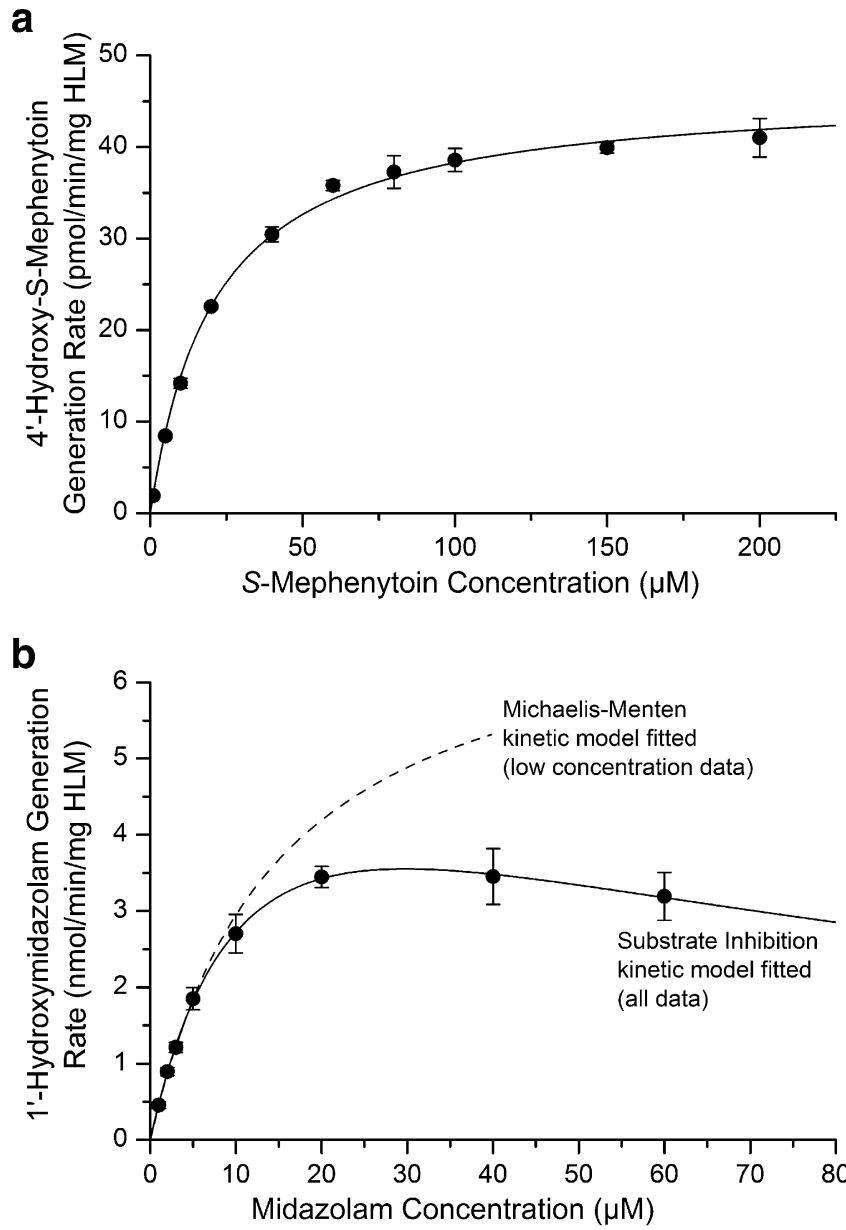

Fig. 1. Examples of human liver microsomal kinetics for $S$-mephenytoin 4'-hydroxylase and midazolam $1^{\prime}$-hydroxylase activities. a Human liver microsomal $S$-mephenytoin $4^{\prime}$-hydroxylation rate data are explained well by the Michaelis-Menten kinetic model over the entire concentration range tested. b In contrast, midazolam $1^{\prime}$-hydroxylase activity data could only be modelled using the Michaelis-Menten kinetic equation at midazolam concentrations up to $\sim 5 \mu \mathrm{M}$. Higher concentration data conformed to substrate inhibition kinetics. For midazolam, only concentrations of up to $\sim 5 \mu \mathrm{M}$ can therefore be used in $\mathrm{IC}_{50}$ and $\mathrm{K}_{\mathrm{i}}$ determinations if data treatments with assumptions based upon Michaelis-Menten kinetics are to be used. [Experimental conditions: $S$ Mephenytoin: 1-200 $\mu \mathrm{M} S$-mephenytoin incubated with $0.5 \mathrm{mg} / \mathrm{ml}$ pooled HLMs (BD-Gentest) and $1 \mathrm{mM} \mathrm{NADPH}$ for $15 \mathrm{~min}$ at $37^{\circ} \mathrm{C}$ in the absence of solvents. Midazolam: 1-60 $\mu \mathrm{M}$ midazolam incubated with $0.15 \mathrm{mg} / \mathrm{mL}$ pooled $\mathrm{HLMs}$, at $37^{\circ} \mathrm{C}$ with $1 \mathrm{mM} \mathrm{NADPH}$ for $5 \mathrm{~min}$ (DMSO content: $0.25 \% \mathrm{v} / \mathrm{v})$ ] 
Non Michaelis-Menten kinetics has been demonstrated for many CYP mediated reactions. This is generally rationalised in terms of the ability of more than one substrate molecule to bind to the enzyme simultaneously, giving rise to both autoactivation and auto-inhibition effects (dependent upon the enzyme, substrate and substrate concentrations). Many academic reports of such atypical kinetics can be found in the literature (14-17) with complex modelling approaches proposed, as well as more straightforward reviews of the topic $(18,19)$.

From a practical point of view, when developing an inhibition assay a combination of enzyme concentration, substrate, substrate concentration and incubation time must be chosen for which:

- Substrate metabolism rate does not change significantly during the incubation (ideally less than $10 \%$ substrate depletion).

- Substrate metabolism is sensitive to the presence of inhibitory compounds (substrate not at saturating concentrations; ideally at, or below, $\mathrm{K}_{\mathrm{M}}$ concentration).

- Sufficient metabolite is generated to be able to quantify enzyme activity even when the enzyme is $95 \%$ inhibited.

- Final solvent content is low enough not to cause dramatic enzyme inhibition $(20,21)$.

- The probability of in vitro activation effects (Fig. 2f) is minimised (choice of substrate, use of $\mathrm{S}_{50}$ rather than lower concentrations for substrates displaying autoactivation kinetics).

\section{CYP Inhibition Measurement: IC $_{50}$ Determination}

The basic assay to assess the interaction potential of a new chemical entity is the $\mathrm{IC}_{50}$ determination. Here, the inhibitory effect of a test compound is measured and the concentration expected to cause $50 \%$ enzyme inhibition reported. The standard method, in which a serial dilution of the test inhibitor in DMSO (or other organic solvent) is performed, maximises the chance that the inhibitor is in solution before being added to the incubation mixture and allows each concentration tested to be as independent of the other measurements as possible. Nevertheless, the highly lipophilic nature of many early lead compounds results in frequent solubility problems. It is therefore important to consider the effect of test inhibitor precipitation after addition to the incubation mixture. Here, four different scenarios can be envisaged: (1) The $\mathrm{IC}_{50}$ is significantly lower than the test inhibitor solubility, resulting in normal inhibition behaviour (Fig. 2a). (2) The $\mathrm{IC}_{50}$ is somewhat lower than, or equal to, the solubility limit: In this case the $\mathrm{IC}_{50}$ can be determined but data points from concentrations above the solubility limit must be excluded (Fig. 2b). An $\mathrm{IC}_{50}$ curve should still be fitted to the data using the 0 and $100 \%$ activity values determined for the experiment as a whole and not fitted to the maximum effect generated by the inhibitor at its saturation concentration in the incubation media (as shown in Fig. 2c). (3) The $\mathrm{IC}_{50}$ is higher than the solubility limit. How clear this will be depends upon the quality of the experimental data, the spacing of the different inhibitor concentrations and the number of data points above the solubility limit (Fig. 2d). "IC $\mathrm{C}_{50}>$ highest concentration where effect was measured with confidence" or " $\mathrm{IC}_{50}$ not deter- mined" should be reported accordingly. (4) Where the $\mathrm{IC}_{50}$ is significantly higher than the solubility limit, a saturated effect profile may be generated (Fig. 2e). With such data, one should not allow an $\mathrm{IC}_{50}$ value of $>50 \mu \mathrm{M}$ (or highest test concentration) to be automatically reported. A clearer picture might be obtained by repeating the experiment using lower inhibitor concentrations.

Given sufficient time and resource, it would be possible to measure the test inhibitor solution concentration in each incubate, or to use nephelometric methods to try to detect precipitation. In practice however, this resource is not normally applied. Flagging of potentially insoluble compounds whose data should be treated with caution can be quickly performed if high throughput solubility (or in silico solubility prediction) data is available. In an analysis of over 5,000 compounds tested for CYP inhibition potency in 2007 using fluorescence-based screening methods, it was observed that the $\mathrm{IC}_{50}$ value reported exceeded the aqueous solubility limit in $20-30 \%$ of all determinations where solubility data was available (Table II). Using a threshold of $\mathrm{IC}_{50}$ /aqueous solubility $>10$ to flag the most potentially erroneous data resulted in identification of between $3 \%$ and $10 \%$ of compounds tested, dependent upon the enzyme assay. Of these, it was most important to consider the $2-7 \%$ of cases whose $\mathrm{IC}_{50}$ values were reported as $>50 \mu \mathrm{M}$ (highest test concentration) as it was more likely that these substances had solubility problems which were not detected. Such substances present a risk of generating misleading structure-activity relationships within a chemical series and perhaps encouraging chemical effort to be directed toward reducing solubility as a way to avoid in vitro enzyme inhibition. A more refined approach to the flagging process could be employed by measuring or predicting the degree of microsomal protein binding and hence comparing the unbound inhibitor concentration with the substance solubility. Formulae for estimation of microsomal protein binding have been proposed by Austin et al (22) and Hallifax and Houston (23).

An accurate and useful screen can be set up by determining the percentage inhibition caused by a test substance at one (or more) defined concentrations (e.g. $3 \mu \mathrm{M})(24,25)$. However, the requirement to re-test compounds of interest means that when developing a screening strategy including compound supply logistics and short turnaround times it is often more efficient simply to perform an $\mathrm{IC}_{50}$ determination for each test substance. In addition, testing at a single inhibitor concentration does not allow deviation from the expected concentration-dependent inhibition effect behaviour to be observed, leaving more scope for the reporting of false negative results due to substance insolubility. The $\mathrm{IC}_{50}$ determination experiment makes no distinction as to whether a compound causes enzyme inactivation or reversible inhibition and cannot distinguish between kinetic mechanisms of reversible inhibition. Further studies therefore need to be performed to characterise the mechanism of inhibition for compounds of interest.

\section{CYP Inhibition Measurement: $K_{\mathbf{i}}$ Determination and Mechanism of Reversible Inhibition}

For inhibitors of substrates which follow MichaelisMenten kinetics tested at the $\mathrm{K}_{\mathrm{M}}$ concentration of substrate, 

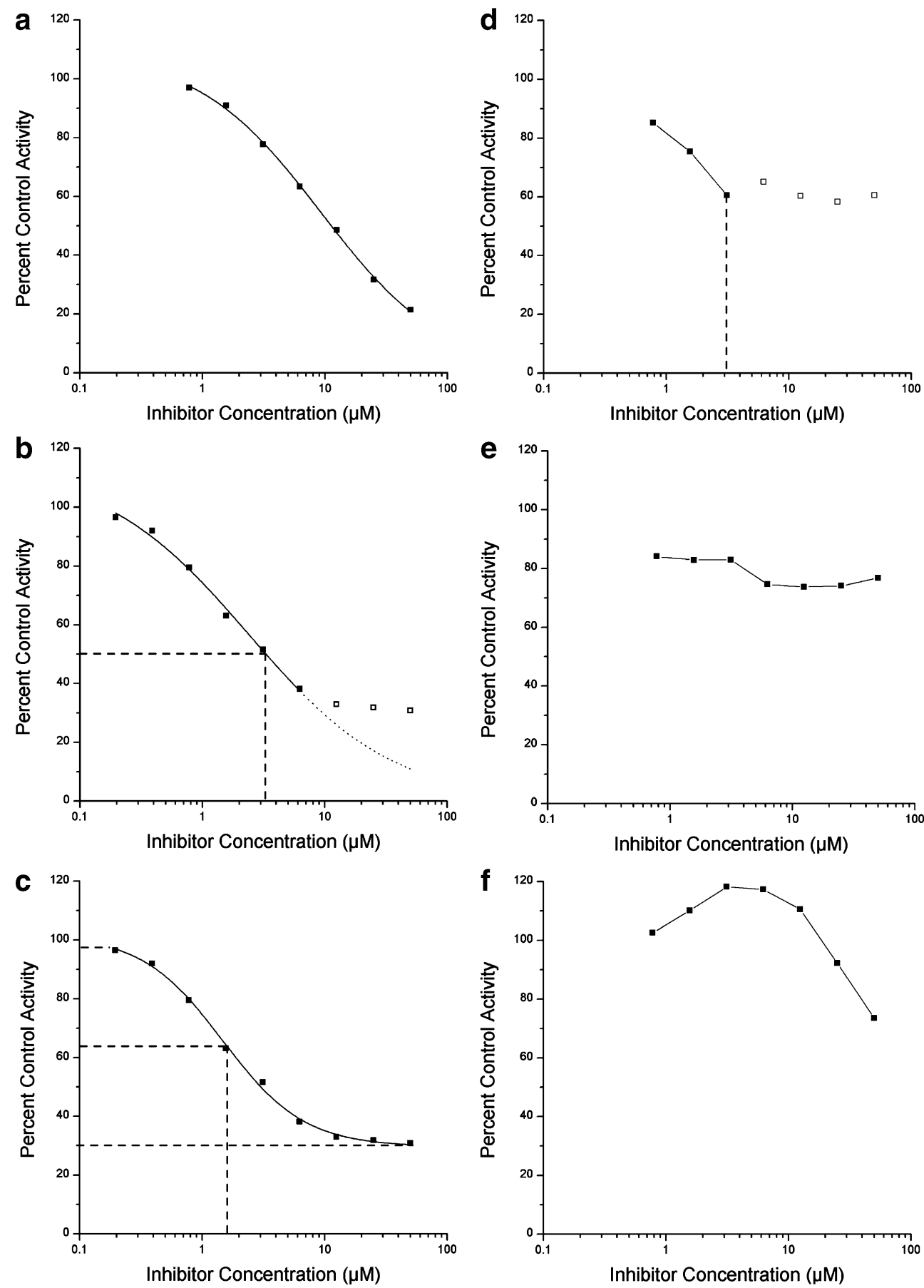

Fig. 2. $\mathrm{IC}_{50}$ data analysis and troubleshooting. Plots of percent control activity against inhibitor concentration (real compound data from HLM midazolam 1'-hydroxylase activity inhibition experiments analysed by LC-MS/MS). a Desired effect profile for $\mathrm{IC}_{50}$ determination; $\mathbf{b}$ Solubility problems prevent use of highest concentration datapoints but $\mathrm{IC}_{50}$ value can still be estimated (full range of enzyme activity used in IC $_{50}$ determination); $\mathbf{c}$ Data as in $\mathbf{b}$, but data processed using measured activity asymptotes for this compound, resulting in an under-estimate of the $\mathrm{IC}_{50}$ value; $\mathbf{d}$ Data difficult to interpret due to solubility limitation, " $\mathrm{IC}_{50}>3 \mu \mathrm{M}$ " or " $\mathrm{IC}_{50}$ not determined" could be reported; e Solubility limit likely to be below lowest inhibitor concentration tested in the experiment. Care should be taken not to automatically assign an $\mathrm{IC}_{50}$ value of $>50 \mu \mathrm{M} ; \mathbf{f}$ In vitro activation indicates inhibitor binding to enzyme at concentrations of $1-$ $10 \mu \mathrm{M}$ exists but $\mathrm{IC}_{50}$ value could not be determined. Inhibition should be assessed using alternative substrates 
$\mathrm{K}_{\mathrm{i}}$ values fall between $\mathrm{IC}_{50} / 2$ (competitive inhibitors) and $\mathrm{IC}_{50}$ (non-competitive inhibitors). $\mathrm{IC}_{50}$ values therefore give sufficient information to have a good indication of the inhibition potency of a potential new drug substance and allow comparison with other candidate molecules. However, for a thorough assessment of DDI effects in vivo, $\mathrm{K}_{\mathrm{i}}$ values are required. The $\mathrm{K}_{\mathrm{i}}$ is dependent upon inhibitor and substrate, but independent of substrate concentration used. Depending on the mode of interaction between CYP enzymes and inhibitors, reversible CYP inhibition may be further described as competitive, noncompetitive, uncompetitive and mixed.

$\mathrm{K}_{\mathrm{i}}$ experiments typically use a matrix of substrate and inhibitor concentrations spanning a range of at least $\sim 0.5-5 \mathrm{x}$ expected $\mathrm{K}_{\mathrm{i}}$ (inhibitor) and $\mathrm{K}_{\mathrm{M}}$ (substrate) concentrations. Data are usually presented in the form of Dixon plots of $1 /$ reaction rate $v s$ inhibitor concentration. $\mathrm{K}_{\mathrm{i}}$ determinations are limited in a practical sense by:

- Inhibitor solubility.

- Limit of detection of inhibited enzyme activity.

- Acceptable turnover limit for substrate to avoid deviation from initial rate conditions (substrate depletion).

- Limit of substrate concentrations which can be tested and remain within the range of Michaelis-Mentenlike kinetics. (Due to allosteric activation, solubility or substrate inhibition effects.)

These restrictions are shown graphically in Fig. 3. As in all graphical solutions generated using $1 /$ rate data, care must be taken to avoid undue influence from the lowest turnover rate data (largest 1/rate values), which typically have the greatest percent variability and are the most subject to allosteric kinetic effects.

Where accurate determinations of enzyme activity have been performed and where Michaelis-Menten kinetics of substrate metabolism is known, accurate estimates of $\mathrm{K}_{\mathrm{i}}$ can be made and a mechanism of inhibition assigned. However, although standard texts $(1,26)$ show clear graphs depicting how the different interaction mechanisms can be assigned, using real data it is often not so easy. In these cases, a straightforward approach to the problem is to make use of a direct plot of reaction rate $v s$ substrate concentration (Fig. 4a) and to assess how the apparent $\mathrm{K}_{\mathrm{M}}$ and $v_{\max }$ values change with increasing inhibitor concentrations, as detailed in Table III.

Once a model has been selected, simultaneous non-linear regression using all the data points can be performed, plots generated of the fitted solution (Fig. 4b) and the solution inspected for the influence of outlier points and consistency of the $\mathrm{K}_{\mathrm{i}}$ and $\mathrm{IC}_{50}$ values (if $\mathrm{IC}_{50}$ previously determined). Once $\mathrm{K}_{\mathrm{i}}$ and mechanism of inhibition have been assigned, extrapolations to expected clinical DDI effect can be attempted, as discussed later.

\section{CYP Inhibition Measurement: Determination of Time-Dependent Inhibition}

Time-dependent inhibition (TDI) is a term which covers any phenomenon resulting in reduction of enzyme activity with incubation time. A detailed description of the kinetic characteristics of this type of inhibition can be found in the text by Silverman (27). Although TDI can arise for a number of reasons (including the formation of potent yet reversiblebinding metabolites (28-30)), the most important molecular mechanisms are:

(1) Generation of reactive electrophiles (typically from furan, thiophene, acetylene and alkene groups) which react with the $\mathrm{P} 450$ to form covalent adducts of the heme or apoprotein, inactivating the enzyme.

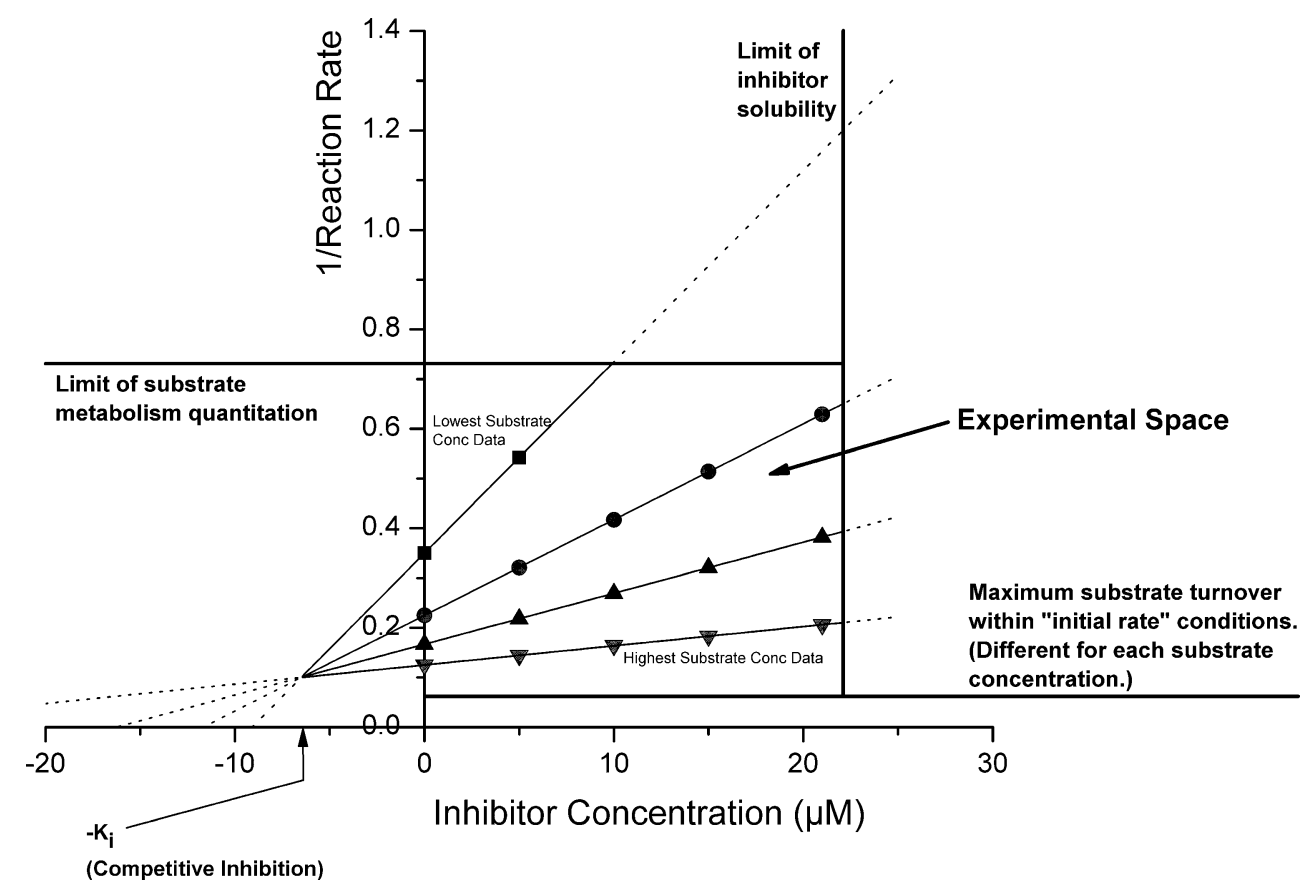

Fig. 3. Experimental restrictions in $K_{i}$ determinations: Substrate depletion-ideally $<10 \%$ metabolism of substrate (and inhibitor) during incubation so little deviation from initial rate conditions. Product detectionlimit of metabolite quantitation (analysis sensitivity). Solubility—both substrate and inhibitor must be in solution 



Fig. 4. $K_{i}$ Determination using all datapoint non-linear regression method. a Direct plot of human liver microsomal S-mephenytoin 4'hydroxylase activity against substrate concentration for each inhibitor concentration tested. Increasing inhibitor concentration resulted in reduced apparent $v_{\max }$ and increased apparent $\mathrm{K}_{\mathrm{M}}$, hence a mixed competitive - non-competitive inhibition model selected and used as shown in Fig. 4b. b Dixon plot of $1 /$ (human liver microsomal Smephenytoin 4'-hydroxylase activity) against inhibitor concentration for each substrate concentration tested, with mixed competitive-noncompetitive inhibition model fitted by non-linear regression using all data simultaneously (Origin 7.03, OriginLab Corp). $\mathrm{K}_{\mathrm{i}}$ and $\mathrm{K}_{\mathrm{i}}{ }^{\prime}$ estimates of $12 \pm 2$ and $24 \pm 2 \mu \mathrm{M}$ were generated

This is often referred to as "suicide inhibition" or "mechanism based inhibition". Here, the enzyme activity cannot be recovered by dialysis of the incubate and a 1:1 stoichiometry of enzyme inactivation and inhibitor-enzyme adduct generation is expected.
(2) The formation of tight-binding complexes between the P450 heme and metabolites of particular chemistries, whose off-rate is so low that the enzyme activity is essentially removed from the in vitro incubation system. Alkylamine and benzodioxazole moieties are the principal functional groups involved here. This is often referred to as "quasi-irreversible" inhibition as CYP activity can be recovered by dialysis (28).

Chemical mechanisms of TDI have been very well reviewed by Kulgutkar, Obach and Maurer (31) and previously by Guengerich (32). Inactivation of CYP enzymes by a compound in vivo can lead to large and long-lasting DDI effects as the metabolic capability can only be restored by new enzyme synthesis, a process taking place over a timescale of days. Detection and amelioration of TDI activity is therefore an important aspect in DDI optimisation for compounds under development. The different experimental methods used for TDI detection, along with their advantages and limitations, are described below.

\section{TDI Methods: IC $_{50}$ Shift on Preincubation}

Assessing whether there is any change in the $\mathrm{IC}_{50}$ value for a test inhibitor with or without inhibitor preincubation with the enzyme system makes a straightforward and useful method for the initial detection of TDI effects. Here, the test inhibitor is incubated with HLMs (or recombinant enzyme) and NADPH (or NADPH regenerating system) for 20$30 \mathrm{~min}$. After this time the substrate is added and the mixture incubated for a further time (normally 3-10 min). Identical incubations are run in parallel lacking the preincubation step (or with preincubation lacking NADPH). $100 \%$ and $0 \%$ activity control incubations are run for each part of the experiment. Plotting percent control enzyme activity against $\log$ (inhibitor concentration) gives sigmoidal inhibition curves for each set of data (Fig. 5). When the inhibition curve is shifted to lower $\mathrm{IC}_{50}$ value by the preincubation treatment, this is an indication of TDI.

The advantages of this method are that it is:

- Straightforward to perform and the data analysis proceeds using the same processing methods as are already established in most labs.

- The data output is fairly clear and little additional knowledge is required to appreciate a positive result in the experiment.

- Many inhibitor concentrations are tested in a single experiment, ensuring that testing in a sensitive region of the concentration-effect curve should occur.

Table III. Kinetic Characteristics of Reversible Inhibition Models

With increasing inhibitor concentration

\begin{tabular}{|c|c|c|c|}
\hline Apparent $\mathrm{K}_{\mathrm{M}}$ & Apparent $v_{\max }$ & Inhibition model & Rate equation \\
\hline Increases & Unchanged & Competitive & $\mathrm{v}=\mathrm{v}_{\max } *[\mathrm{~S}] /\left\{\left(\mathrm{K}_{\mathrm{M}} *\left(1+[\mathrm{I}] / \mathrm{K}_{\mathrm{i}}\right)\right)+[\mathrm{S}]\right\}$ \\
\hline $\begin{array}{l}\text { Increases }\left(\mathrm{K}_{\mathrm{i}}^{\prime}>\mathrm{K}_{\mathrm{i}}\right) \\
\text { Decreases }\left(\mathrm{K}_{\mathrm{i}}^{\prime}<\mathrm{K}_{\mathrm{i}}\right)\end{array}$ & Decreases & Mixed competitive/non-competitive & $\mathbf{v}=\mathbf{v}_{\max } *[\mathrm{~S}] /\left\{\left(\mathrm{K}_{\mathrm{M}} *\left(1+[\mathbf{I}] / \mathrm{K}_{\mathrm{i}}\right)\right)+\left([\mathrm{S}] *\left(1+[\mathrm{I}] / \mathrm{K}_{\mathrm{i}}^{\prime}\right)\right)\right\}$ \\
\hline Unchanged & Decreases & Non-competitive & $\mathbf{v}=\mathbf{v}_{\max } *[\mathbf{S}] /\left\{\left(\mathrm{K}_{\mathrm{M}} *\left(1+[\mathbf{I}] / \mathrm{K}_{\mathrm{i}}\right)\right)+\left([\mathrm{S}] *\left(1+[\mathrm{I}] / \mathrm{K}_{\mathrm{i}}\right)\right)\right\}$ \\
\hline Decreases & Decreases & Uncompetitive & $\mathbf{v}=\mathbf{v}_{\max } *[\mathbf{S}] /\left\{\mathbf{K}_{\mathbf{M}}+\left([\mathbf{S}] *\left(1+[\mathbf{I}] / \mathbf{K}_{\mathrm{i}}\right)\right)\right\}$ \\
\hline
\end{tabular}



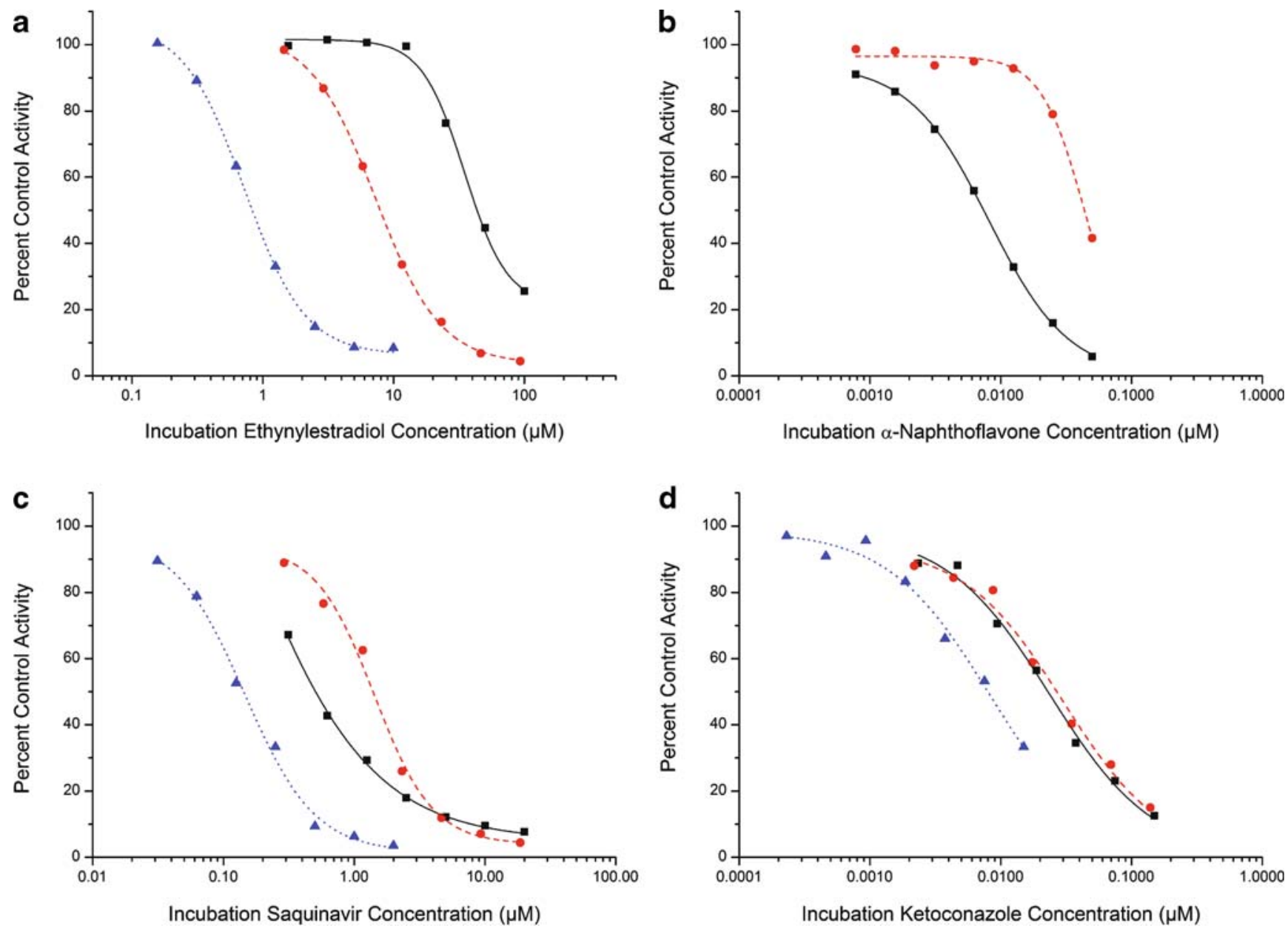

Fig. 5. Examples of $\mathrm{IC}_{50}$ shift assay for detecting TDI: a Inhibition of human liver microsomal midazolam $1^{\prime}$-hydroxylase activity by $17 \alpha$ ethynylestradiol. Rightmost curve (squares and solid line, $\left.\mathrm{IC}_{50}=49 \mu \mathrm{M}\right)$ : determination with no preincubation $(0.2 \mathrm{mg} / \mathrm{ml} \mathrm{HLM}, 5 \mathrm{~min}$ incubation time). Centre curve (circles and dashed line, $\mathrm{IC}_{50}=8.3 \mu \mathrm{M}$ ): determination with 30 min preincubation in the absence of substrate $\left(0.25 \mathrm{mg} / \mathrm{ml} \mathrm{HLM}\right.$ in preincubation, $0.2 \mathrm{mg} / \mathrm{ml} \mathrm{HLM} \mathrm{in} \mathrm{incubation,} 5 \mathrm{~min}$ incubation time). Leftmost curve (triangles and dotted line, $\mathrm{IC}_{50}=$ $0.89 \mu \mathrm{M})$ : determination with $30 \mathrm{~min}$ preincubation and 10 -fold dilution before incubation $(0.2 \mathrm{mg} / \mathrm{ml} \mathrm{HLM} \mathrm{in} \mathrm{preincubation,} 0.02 \mathrm{mg} / \mathrm{ml} \mathrm{HLM}$ in incubation, $5 \mathrm{~min}$ incubation time). b Experiment examining $\alpha$-naphthoflavone inhibition of human liver microsomal ethoxyresorufin Odeethylase activity (principally CYP1A2 mediated). Squares and solid line: no preincubation, circles and dashed line: with 30 min preincubation. Preincubation resulted in metabolism of $\alpha$-naphthoflavone but not in enzyme inactivation, so curve shifted to higher IC $\mathrm{C}_{50}$ value. $\mathbf{c} \mathrm{Human}_{\mathrm{iver}}$ microsomal midazolam 1'-hydroxylase activity inhibition by saquinavir. Squares and solid line: no preincubation; circles and dashed line: 30 min preincubation, metabolism of saquinavir in lower concentration incubations outweighs enzyme inactivation so curve shifted to higher $\mathrm{IC}_{50}$ value and sigmoidicity increased; triangles and dotted line: $30 \mathrm{~min}$ preincubation and 10-fold dilution allows enzyme inactivation effect to become apparent. d: Human liver microsomal midazolam 1'-hydroxylase activity inhibition by ketoconazole. Squares and solid line: no preincubation; circles and dashed line: $30 \mathrm{~min}$ preincubation — no change in apparent inhibition potency as enzyme not inactivated; triangles and dotted line: 30 min preincubation and 10-fold dilution-curve shift to lower $\mathrm{IC}_{50}$ value due to enzyme/protein dilution

Disadvantages are that:

- Enzyme inactivation continues during the incubation phase of the experiment.

- Generation of metabolites which are more inhibitory than the parent substance will look like TDI.

- The reverse effect (shift of curve to higher $\mathrm{IC}_{50}$ value) can occur where the test inhibitor is significantly depleted without enzyme inactivation (Fig. 5b and $\mathrm{c}$ ). This can be seen for highly metabolically unstable compounds and substances tested at very low concentrations. A balance between test substance metabolism (to non-inhibitory products) and enzyme inactivation may look like no inhibition effect.
- Assay variability must be small enough to allow a detectable $\mathrm{IC}_{50}$ shift to be generated by low potency TDI substances.

An enhanced version of this assay in which both a preincubation and a dilution are performed gives the capacity to leverage the enzyme inactivation effect to produce more dramatic $\mathrm{IC}_{50}$ shifts, to reduce the potential problem of inhibitory metabolite generation (by dilution away from enzyme) and potentially to enhance the method sensitivity (33) (Fig. 5). The utility of this method can be seen for saquinavir (Fig. 5c), where the dilution effect allows enzyme inactivation to be detected despite substantial inhibitor metabolism. However, some care must be taken not to 
introduce artefacts into an otherwise straightforward experimental protocol. For instance, when ketoconazole is tested in this way an $\mathrm{IC}_{50}$ shift due to changes in enzyme and protein concentration can be seen (Fig. 5d). If HLM dilution is made into protein solution, this effect is substantially reduced.

\section{TDI Methods: Following Reaction Progress Curves (Kinetic Measurement Protocol)}

A seldom applied method (recently been exemplified in a study by Fairman et al (34)) observes the change in metabolism rates with incubation time in the presence of different inhibitor concentrations. It can either be performed using a large number of individual endpoint measurements or by using a fluorescence plate reader running in kinetic mode. The progress curve method has the advantage of allowing TDI to be detected in the same experiment as the $\mathrm{IC}_{50}$ determination. A large number of datapoints need to be generated and simultaneous fitting of all the data is then used to estimate $K_{i}, K_{I}$ and $k_{\text {inact }}$ values. The method has the disadvantages that:

- Either pro-fluorescent substrates must be used in order to allow kinetic measurements in real time or a large number of samples must be measured using LCMS/MS, luminescence, radioactivity or other endpoint measurement technologies.

- Very high signal measurement sensitivity and accuracy are required to allow changes in the rate of metabolite generation throughout the incubation to be observed, especially where enzyme activity is low (due to high levels of competitive inhibition).

- Substrate competes with inhibitor to bind to the P450, partially shielding the enzyme from inactivation.

- Generation of inhibitor metabolites more potent than the test inhibitor will give the appearance of TDI.

\section{TDI Methods: Preincubation-Dilution-Incubation Method}

This is the classical method of determining TDI effects (35). After different preincubation times, aliquots of the enzyme-inhibitor mix are diluted into substrate solution and the remaining enzyme activity determined. The method has the distinct advantages that the inhibitor (and its metabolites) can be diluted away from the enzyme at the end of the preincubation time, minimising further enzyme inhibition and allowing enzyme inactivation to be distinguished from inhibitory metabolite generation. Data outputs are the inactivation rate constants $\left(k_{\mathrm{obs} \text { (inhibitor, conc })}=-\right.$ slope in plot of $\ln$ (activity) vs preincubation time) and percent timedependent enzyme inactivation following a given preincubation time. The assay can be deployed in both screening and kinetic characterisation modes: In a screening mode, many substances can be each tested at a single concentration, e.g. $10 \mu \mathrm{M}$, and the $k_{\text {obs }}$ values compared within a chemical series or against absolute values benchmarked using known TDI positive substances (e.g. $<0.005 \mathrm{~min}^{-1}$ within background noise, $0.005-0.025 \mathrm{~min}^{-1}$ moderate TDI substances, $>0.025 \mathrm{~min}^{-1}$ highly positive TDI substances). Where a positive result is found for a compound of interest, a kinetic characterisation of the TDI effect should be performed, in order to estimate the TDI effect at clinically relevant concentrations.

In a TDI kinetic characterisation, $k_{\text {obs }}$ values are determined for many inhibitor concentrations, and hence the kinetic constants $k_{\text {inact }}$ (maximal rate of enzyme inactivation) and $\mathrm{K}_{\mathrm{I}}$ (concentration of inhibitor giving half-maximal enzyme inactivation rate) estimated (Fig. 6). A hyperbolic model $\left(k_{\text {obs }}=k_{\text {inact }} *[I] /\left(K_{I}+[I]\right)\right)$ readily allows $k_{\text {inact }}$ and $\mathrm{K}_{\mathrm{I}}$ estimation, with a good fit to the experimental data achieved for most compounds. Ghanbari et al have shown that many published studies of TDI which followed this method were limited by insufficient enzyme dilution and over-long incubation times (36). However, with increased LCMS/MS method sensitivity it is possible to minimise the
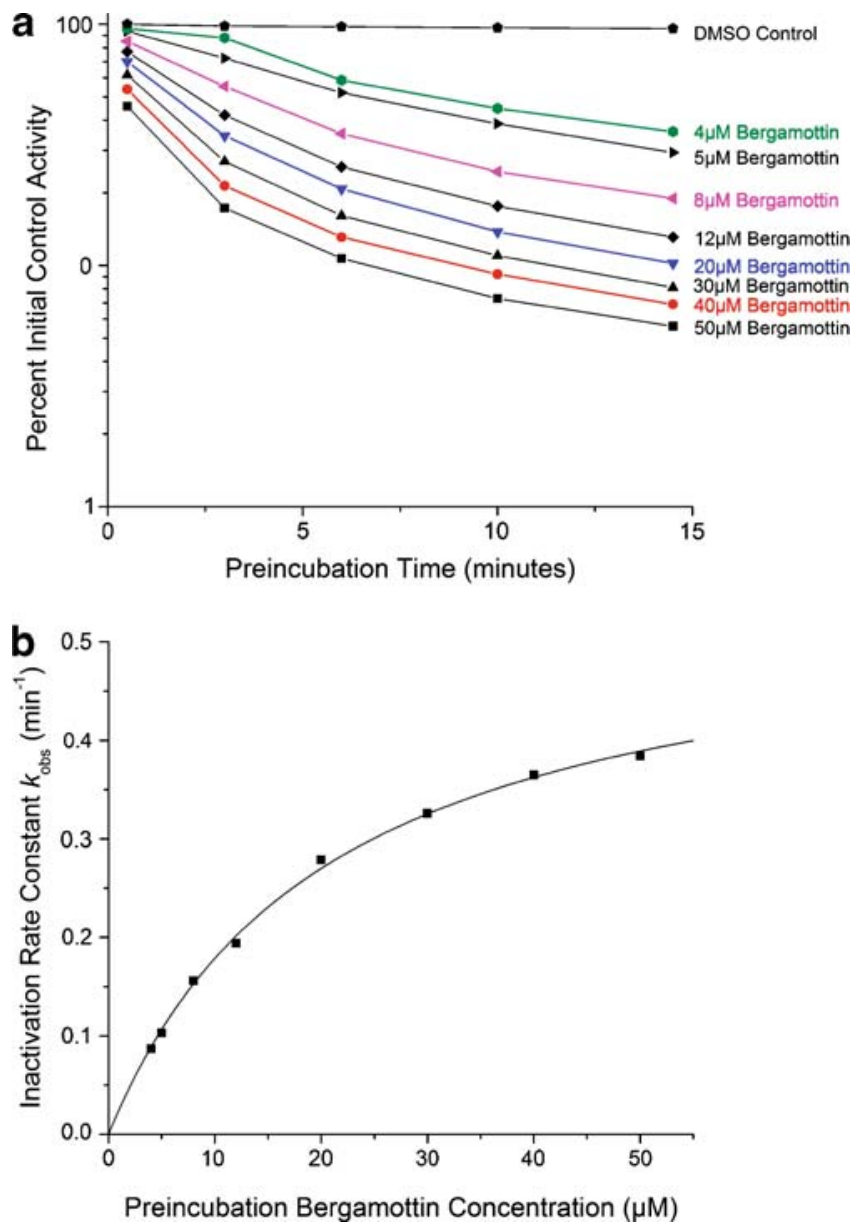

Fig. 6. TDI of human liver microsomal midazolam 1'-hydroxylase activity by bergamottin. Preincubation performed using $1 \mathrm{mg} / \mathrm{ml}$ HLM (pooled, BD-Gentest) $1 \mathrm{mM}$ NADPH and $0-50 \mu \mathrm{M}$ bergamottin. Aliquots diluted 10-fold to make incubations (10 min) containing $10 \mu \mathrm{M}$ midazolam, $0.1 \mathrm{mg} / \mathrm{ml} \mathrm{HLM}$ and $1 \mathrm{mM}$ NADPH. a Activity decay profiles for each test concentration; Inactivation rate constants calculated from plots of $\ln$ (percent initial control activity) against preincubation time. First two (three for lowest bergamottin concentrations) datapoints used for initial inactivation rate estimations. b Non-linear regression of formula $k_{\text {obs }}=\left(k_{\text {inact }} * I\right) /\left(K_{I}+I\right)$ using Origin v7.03 (OriginLab Corp) gave estimates of $K_{\mathrm{I}}=21 \pm 1 \mu \mathrm{M}$ and $k_{\text {inact }}=0.55 \pm 0.01 \mathrm{~min}^{-1}$ 
residual effect of the inhibitor after the dilution step by using a dilution factor of 20- (or even 50-) fold, with incubation times of 3-5 min. These improvements should reduce the bias possible in many TDI experiments where the incubation time was comparable to the preincubation time and dilution factors of less than 10 were sometimes used. In addition, preincubation times need to be tuned to the inhibitor investigated: highly effective TDI substances require short preincubation times in order to inactivate the first $90 \%$ of enzyme activity which is most accurately measured, whereas less effective TDI substances require substantial preincubation times to generate sufficient enzyme inactivation for measurement. Generic TDI determination methods must therefore include a combination of both short and longer preincubations times.

\section{PROBLEMS WITH CYP INHIBITION DATA-DIFFERENT RESULTS FROM DIFFERENT SYSTEMS}

In theory, the same $\mathrm{IC}_{50}$ value should be generated for inhibition of the same enzyme when performed under the same conditions (protein concentration, solvent concentration, buffer, enzyme source) if different substrates are used at the $\mathrm{K}_{\mathrm{M}}$ concentration. However, this is often not the case in practice. In CYP inhibition screening, this phenomenon is principally due to two separate problems: Firstly, high variability exists in the degree of correlation between inhibition data generated using recombinant enzymes and fluorescent probe substrates and those generated using HLMs and classical (often referred to as 'drug-like') substrates. Secondly, there are differences in inhibition activities of test compounds, dependent upon the substrate chosen for some CYPs, especially CYP3A4. Both of these problems and their consequences are discussed below.

\section{Requirement for Correlation Between Assay Systems}

The human liver microsomal assay is accepted as the 'gold standard' for in vitro DDI assessment as it is felt to be closest to the native enzyme environment without the batch variability, potential transporter involvement and cell penetration complications associated with human hepatocytes. This assay is therefore used to characterise development compounds where data will be submitted to regulatory authorities. In companies where additional assay systems (typically fluorescence-based) are used for early discovery stage high throughput CYP inhibition screening, there is a need to ensure that the data generated by the screening and regulatory assays correlate. Unfortunately, this is not always the case for many project chemistries under development today, which may call into question the utility of data generated using profluorescent probe substrates, despite the technically excellent nature of the assay (in terms of sensitivity, speed, costeffectiveness and reproducibility). Awareness of the reasons for such discrepancies and individual project guidance are therefore needed when dealing with CYP inhibition problems during lead optimisation (Fig. 7). Effects contributing to differences in data between assay types are discussed below.

Differences in protein, lipid and co-enzyme content. It is normally assumed that only the inhibitor and substrate which are free in solution are available to interact with the enzyme system. As the recombinant enzymes often have a much higher P450 content per milligram protein than HLMs, there can be a significant difference in the amount of total protein required to run an inhibition assay. The sensitivity of $\mathrm{IC}_{50}$ values to microsomal concentration has been observed for many compounds and particularly well characterised in the case of montelukast, a CYP2C8 selective inhibitor (37). Here, a 10 -fold increase in $\mathrm{IC}_{50}$ value was observed when the human
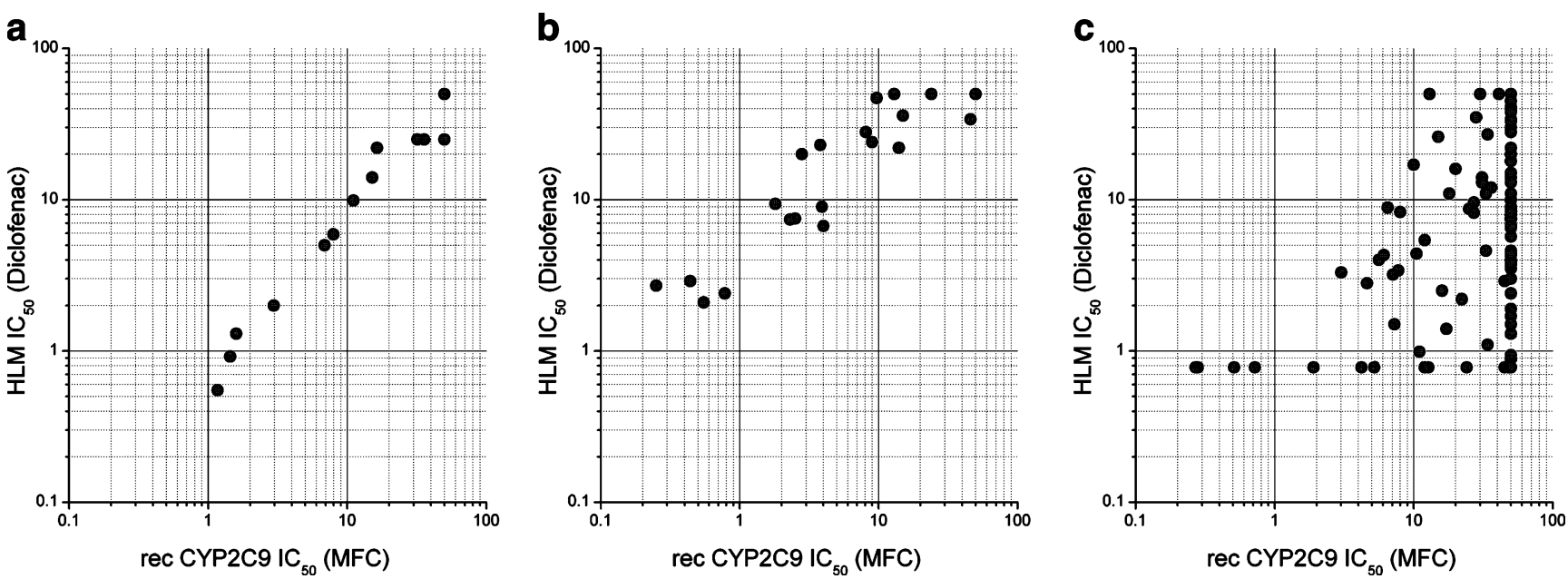

Fig. 7. Comparison of $\mathrm{IC}_{50}$ values generated using recombinant $\mathrm{CYP} /$ pro-fluorescent substrate and HLM/'drug-like' substrate. Comparison of $\mathrm{IC}_{50}$ data generated using recombinant CYP2C9 $(50 \mathrm{pmol} / \mathrm{ml}$ E. coli expressed CYP2C9, 15 min incubation time, MFC as substrate) and with those generated using HLMs $(0.2 \mathrm{mg} / \mathrm{ml}$ pooled HLMs (BD-Gentest), $5 \mathrm{~min}$ incubation time, $5 \mu \mathrm{M}$ diclofenac as substrate) for three chemically different discovery phase research projects. Ranges of $\mathrm{IC}_{50}$ interpolation for each assay were $0.2-50 \mu \mathrm{M}$ (recombinant $\mathrm{CYP}$ ) and $0.7-50 \mu \mathrm{M}$ (HLM). a Essentially perfect correlation $(n=14)$ - screening assay can be used routinely for optimisation. b Fair correlation with some scatter and a systematic shift towards higher $\mathrm{IC}_{50}$ values in the human liver microsomal assay $(n=22)$ - screening assay can be used, with testing of most interesting compounds in HLM assay. $\mathbf{c}$ No correlation and gross underestimation of the CYP inhibition potential by the fluorescencebased assay $(n=136)$ —extensive use of HLM assay required as fluorescence based screening assay not predictive 
liver microsomal content was changed from 0.1 to $1 \mathrm{mg} / \mathrm{ml}$. Although additional protein may be added to recombinant enzyme experiments to try to avoid differential protein binding effects, this is not always done and, even where it is, the type of protein which is added (e.g. mock transfected recombinant system protein, human serum albumin) may not completely prevent differential protein binding effects. Where calculations of the free $\mathrm{IC}_{50}$ values have been made, these are often an order of magnitude lower than the measured $\mathrm{IC}_{50}$ values, even where low human liver microsomal concentrations have been used (12). Another reason not to expect identical behaviour from HLM and recombinantly expressed enzymes systems is that quite different amounts of CYP reductase and cytochrome $b_{5}$ per CYP molecule exist, resulting in differential catalysis rates and degrees of uncoupling.

Effect of P450 content. The effects of binding to the target enzyme are seen with extremely potent inhibitors of relatively abundant CYPs such as ketoconazole (CYP3A4/ CYP3A5) and alpha-naphthoflavone (CYP1A2), whose IC $_{50}$ values change in proportion to enzyme content. Here, the assumption that total inhibitor concentration and free inhibitor concentration are approximately the same is violated, and at low inhibitor concentrations there may be a titration of inhibitor with almost stoichiometric binding to enzyme at the $\mathrm{IC}_{50}$ concentration. With reduction in total human liver microsomal protein (enzyme) concentration there has therefore been a reduction in $\mathrm{IC}_{50}$ values determined for the most potent CYP inhibitors.

Inhibitor Metabolism. Often discussed, but rarely investigated is the extent of inhibitor metabolism which occurs during the incubation. If a significant proportion of the inhibitor is metabolised by HLMs compared to a recombinant enzyme system (or vice versa) and the average inhibition effect is measured over the total incubation time, there will obviously be differences in the $\mathrm{IC}_{50}$ values generated. A recent report showed that considerable inhibitor metabolism may occur when using $0.5 \mathrm{mg} / \mathrm{ml} \mathrm{HLM}$ and $20 \mathrm{~min}$ incubation time (24). This was proposed as one of the main reasons for differences in HLM and recombinant CYP $\mathrm{IC}_{50}$ data. However, in modern CYP inhibition protocols, where typical HLM concentrations of $0.05-0.2 \mathrm{mg} / \mathrm{ml} \mathrm{HLM}$ and incubation times of 3-5 min are used (9), this should be considerably less problematic.

Where there is significant inhibitor turnover, there is also the possibility that metabolites more inhibitory than the parent substance are generated in significant quantities. Apart from the instances discussed in the section about TDI, this is not the norm. There is, after all, a strong element of lipophilicity associated with CYP inhibition structureactivity relationships, and when a compound is hydroxylated the product typically has a lower affinity for the enzyme than the parent molecule. Where this does not happen, the product may well undergo a second (or third) metabolic transformation before release from the enzyme.

\section{Differential Substrate Binding and Hence Differential Inhibitor Interactions}

This phenomenon is best characterised for CYP3A4, where it has long been known that substrate dependence in
$\mathrm{IC}_{50}$ values occurred. In a systematic study of the effect by Kenworthy et al (38), the correlation between inhibition data generated using 10 different CYP3A substrates was analysed, with some substrates found to behave similarly whilst others showed quite different patterns of inhibition sensitivity. Chemically varied CYP3A substrates representative of the diversity in prescribed drug substances should therefore be used to ensure adequate assessment of CYP3A4 inhibition potential. Typically three compounds, such as midazolam, nifedipine and testosterone are used. The differential inhibition effects of an example drug candidate molecule are shown in Fig. 8a. However, it is worth remembering that significantly different inhibition effects are "known outliers" in an otherwise reasonable correspondence of $\mathrm{IC}_{50}$ values obtained when similar assay protocols and different substrates are used (Fig. 8b).

One rationale of the differential inhibition effects which has gained popular acceptance is that CYP3A4 possesses 3 different binding sites. Perhaps more correctly, once could say
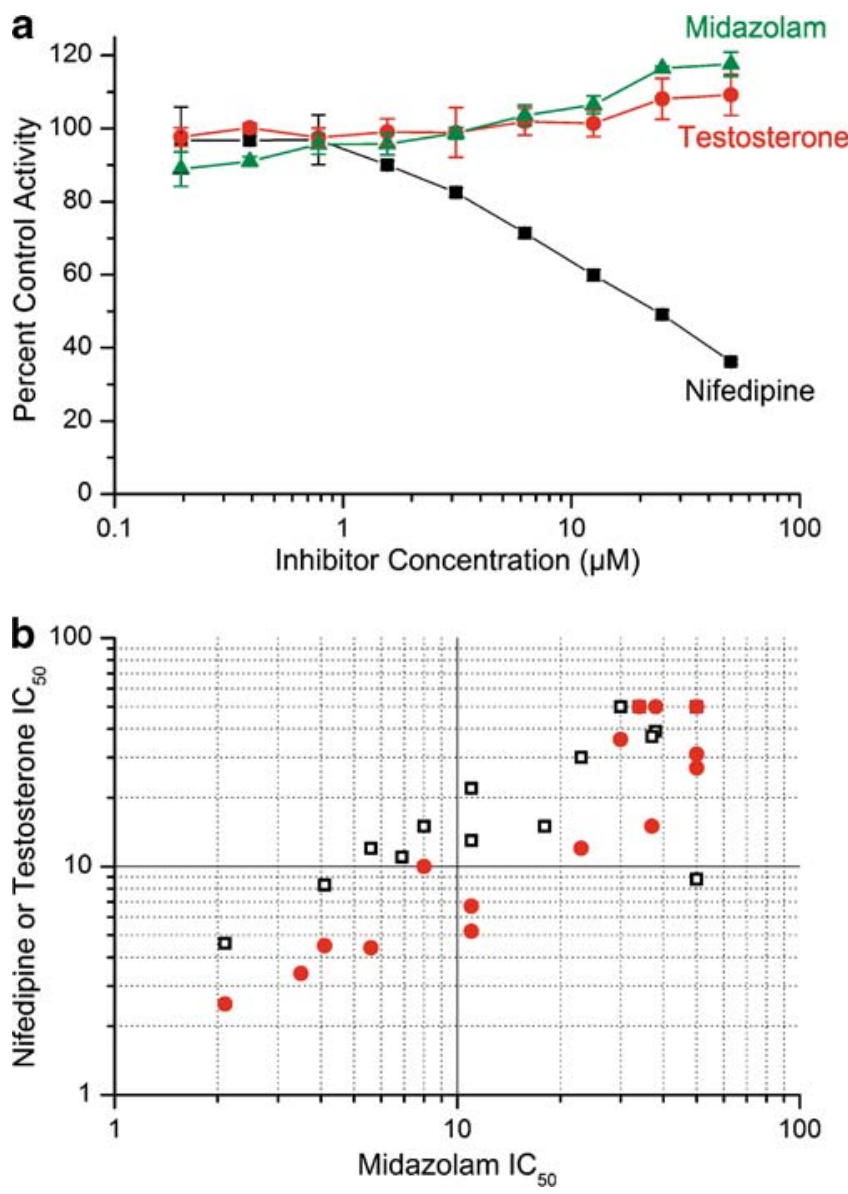

Fig. 8. Differential $\mathrm{IC}_{50}$ Value Determinations using Different CYP3A4/5 Substrates. a Example of substrate-selective CYP3A4/5 inhibition: no inhibition effect seen using either midazolam (triangles) or testosterone (circles), but clear inhibition of nifedipine oxidase activity (squares). b Correlation of $\mathrm{IC}_{50}$ data for 31 (testosterone, filled circles) or 35 (nifedipine, open squares) structurally diverse test inhibitors with midazolam $\mathrm{IC}_{50}$ values indicates a generally good agreement between the assays. Incubations were performed using $0.2 \mathrm{mg} / \mathrm{ml}$ pooled HLMs, $1 \mathrm{mM} \mathrm{NADPH}$, incubation time of $5 \mathrm{~min}$ and substrate concentrations of $5 \mu \mathrm{M}$ midazolam, $10 \mu \mathrm{M}$ nifedipine or $30 \mu \mathrm{M}$ testosterone 
that the active site is sufficiently large as to allow binding of substrate molecules to different regions, all of which may be able to access the active site, but with differential binding characteristics. This hypothesis is consistent with the allosteric and heterotrophic enhancement effects often seen in CYP3A4 enzyme kinetics (18). Indeed, there is kinetic evidence that CYP3A4 can bind three molecules simultaneously. In addition, crystallography studies have shown that the enzyme possesses an extended active site generally devoid of specific ligand-binding residues which allows a complex mode of interaction with substrate, activator and inhibitor molecules to exist (39).

\section{USE OF CYP INHIBITION DATA: RANKING, EXTRAPOLATION AND DDI PREDICTION}

In the earliest phases of hit identification and lead optimisation, $\mathrm{IC}_{50}$ and single concentration $k_{\mathrm{obs}}$ data can be used to rank compounds, identify problematic chemistries for further optimisation and develop structure-activity relationships. (Many structure-activity relationships $(40,41)$ and discussions of substrate binding interactions (42) have been published for different CYPs; these will not be discussed further in this review.) Little or no DDI prediction is needed in the earliest lead optimisation phases, as absolute values $\left(\mathrm{IC}_{50}>1 \mu \mathrm{M}, k_{\mathrm{obs}}(10 \mu \mathrm{M})<0.005 \mathrm{~min}^{-1}\right.$ for CYPs $1 \mathrm{~A} 2,2 \mathrm{C} 9$, 2C19, 2D6 and 3A4) make reasonable optimisation targets. As compounds progress towards candidate selection, an assessment of the different DDI risks which compounds pose must take into account the expected therapeutic concentrations. A good example of this approach where both reversible and time dependent inhibition data are brought together has recently been given by Obach et al. (33).

For a prediction of the expected clinical DDI effect, increasingly sophisticated approaches have been applied. Changes in the area under the plasma concentration-time curve (AUC) of an oral drug are generally described by the following equation (43) (Eq. 1):

$$
\begin{aligned}
& A U C_{P O(I)} / A U C_{P O(C)} \\
& \quad=\left(f a^{\prime} / f a\right) \cdot\left(f g^{\prime} / f g\right) \cdot\left(f h^{\prime} / f h\right) \cdot\left(C L t o t / C L t o t^{\prime}\right)
\end{aligned}
$$

where $\mathrm{AUC}_{\mathrm{po}(\mathrm{c})}, \mathrm{AUC}_{\mathrm{po}(\mathrm{I})}, \mathrm{f}_{\mathrm{a}}, \mathrm{f}_{\mathrm{a}}{ }^{\prime}, \mathrm{f}_{\mathrm{g}}, \mathrm{f}_{\mathrm{g}}{ }^{\prime}, \mathrm{f}_{\mathrm{h}}, \mathrm{f}_{\mathrm{h}}{ }^{\prime}, \mathrm{CL}_{\text {tot }}$, and $\mathrm{CL}_{\text {tot }}{ }^{\prime}$ are the area under the plasma concentration-time curve, fraction of dose absorbed, fraction of the dose escaping gut metabolism, fraction of the dose escaping hepatic metabolism, and total hepatic clearance in the absence and presence of a CYP inhibitor, respectively. Equation 1 can be simplified if liver is the only organ responsible for the metabolic clearance, the CYP inhibitor does not interfere with drug absorption and no or minimal gut metabolism and renal clearance are involved. Therefore, the following equation (Eq. 2) can be applied when a well-stirred model is considered $\left(\mathrm{S}<<\mathrm{K}_{\mathrm{M}}\right)$ :

$$
\begin{aligned}
& A U C_{P O(I)} / A U C_{P O(C)} \\
& \quad=1 /\left[\left\{f m \cdot f m_{C Y P} /\left[C L_{\operatorname{int}(C)} / C L_{\operatorname{int}(I)}\right]\right\}+\left\{1-f m \cdot f m_{C Y P}\right\}\right]
\end{aligned}
$$

where $\mathrm{f}_{\mathrm{m}}, \mathrm{f}_{\mathrm{m}, \mathrm{CYP}}, \mathrm{CL}_{\mathrm{int}(\mathrm{I})}$ and $\mathrm{CL}_{\mathrm{int}(\mathrm{C})}$ represent fraction of the dose metabolized, fraction of the dose metabolized by CYP, intrinsic clearance in the presence of an inhibitor, and intrinsic clearance in the absence of an inhibitor, respectively. Simulations based on Eq. 2 indicate clearly that the change in AUC $\left(\mathrm{AUC}_{\mathrm{po}(\mathrm{I})} / \mathrm{AUC}_{\mathrm{po}(\mathrm{C})}\right.$ ratio) is sensitive to the product of $\mathrm{f}_{\mathrm{m}}$ and $\mathrm{f}_{\mathrm{m}, \mathrm{CYP}}$ (i.e., $\mathrm{f}_{\mathrm{m}} \cdot \mathrm{f}_{\mathrm{m}, \mathrm{CYP}}$ ) (44-46). Although not obvious, it is worth noting that changes in AUC are also sensitive to the $\mathrm{CL}_{\text {int }}$ in the absence of the inhibitor.

Mode of inhibition-reversible inhibition. Depending on the kinetic behaviour of enzyme, substrate and inhibitor, reversible CYP inhibition can be described as competitive, non-competitive, un-competitive and mixed (47). Cases of competitive inhibition are most frequently assessed. Here, the $\mathrm{AUC}_{\mathrm{PO}(\mathrm{I})} / \mathrm{AUC}_{\mathrm{PO}(\mathrm{C})}$ ratio can be expressed as (Eq. 3):

$$
\begin{aligned}
& A U C_{P O(I)} / A U C_{P O(C)} \\
& \quad=1 /\left[\left\{f m \cdot f m_{C Y P} /\left[1+\left([I] / K_{I}\right)\right]\right\}+\left\{1-f m \cdot f m_{C Y P}\right\}\right]
\end{aligned}
$$

Where $[\mathrm{I}]$ and $\mathrm{K}_{\mathrm{i}}$ are the inhibitor concentration at the site of inhibition and the inhibition constant, respectively. The inhibitor concentration, [I], is often based on plasma concentrations because concentrations at the site of inhibition cannot be measured $(47,44)$. Because of this, various inhibitor concentrations including plasma $\mathrm{C}_{\max }$, plasma free $\mathrm{C}_{\max }$, portal vein $\mathrm{C}_{\max }$ (inlet liver concentration) and portal vein free $\mathrm{C}_{\max }$ have been explored for prediction accuracy $(44,47-49)$. In some cases, the use of portal vein $\mathrm{C}_{\max }$ is fairly accurate in DDI prediction and for other compounds the portal vein free $\mathrm{C}_{\max }$ or plasma $\mathrm{C}_{\max }$ is reasonable as well. In addition, physiologically based pharmacokinetic models have been examined, which take into consideration dynamic (as opposed to static) inhibitor concentrations (50). Furthermore, absorption rate constants of CYP inhibitors may be incorporated into the prediction model, leading to a reduction in overprediction for some CYP2D6 and CYP3A4 substrates $(44,51)$.

Mode of inhibition-mechanism-based inactivation. Mechanism-based CYP inhibition or irreversible inhibition, involves permanent inactivation of CYP enzymes. Prediction of in vivo drug interactions for mechanism-based inhibitors is more complex and modified equations are therefore required to take into account the balance between enzyme inactivation and new enzyme synthesis. For mechanism-based inactivation, the $\mathrm{AUC}_{\mathrm{PO}(\mathrm{I})} / \mathrm{AUC}_{\mathrm{PO}(\mathrm{C})}$ ratio is described as (Eq. 4) (52):

$$
\begin{aligned}
& A U C_{P O(I)} / A U C_{P O(C)} \\
& =1 /\left[\left\{f m_{f} \cdot f m_{C Y P} /\left[1+\left(k_{\text {inact }} / k_{\mathrm{deg}}\right) *\left([I] / K_{I}\right)\right]\right\}+\left\{1-f m \cdot f m_{C Y P}\right\}\right]
\end{aligned}
$$

Where $k_{\text {inact }}, \mathrm{K}_{\mathrm{I}}$ and $k_{\text {deg }}$ represent the maximal rate of enzyme inactivation at saturation, concentration of inhibitor that produces half maximal inactivation, and turnover rate of the inhibited enzyme, respectively. Values of $k_{\text {inact }}$ and $\mathrm{K}_{\mathrm{I}}$ can be determined experimentally (35) and $k_{\mathrm{deg}}$ for each CYP enzymes is often assigned based on values reported in the literature. Galetin et al (45) examined a wide range of $k_{\mathrm{deg}}$ values $\left(0.0005\right.$ to $\left.0.00008 \mathrm{~min}^{-1}\right)$ for CYP3A4 and found that a $k_{\mathrm{deg}}$ of $0.00016 \mathrm{~min}^{-1}$ yielded an $89 \%$ success rate (defined by $<2$-fold of observed in vivo values) of predicting mechanismbased inactivation. However, uncertainties in experimental design and data generation $\left(k_{\text {inact }}, \mathrm{K}_{\mathrm{I}}\right.$ and $\left.k_{\mathrm{deg}}\right)$, inhibitor 
concentration used (for example, plasma $\mathrm{C}_{\max } v s$. portal vein $\mathrm{C}_{\max }$ ), and quality of clinical drug interaction data may contribute to discrepancies in the prediction (33).

Parallel pathways. The value of $\mathrm{f}_{\mathrm{m}, \mathrm{CYP}}$ is the most important parameter for the prediction of in vivo drug interactions. It is well recognized that a substrate cleared primarily by a single CYP enzyme $\left(f_{m, C Y P}>0.8\right)$ has a far greater potential for DDIs than those eliminated via multiple metabolic or excretory pathways. Ito et al (53) recently examined the impact of parallel pathways for the prediction of in vivo interactions for CYP2D6 substrates and found that the number of over-predictions was significantly reduced by incorporating an additional pathway. The model was also useful in investigation the role of CYP2D6 polymorphism in the prediction of DDIs and has been extended for other CYPs $(45,51)$. It is clear that the accuracy of prediction can be improved with the consideration of additional clearance pathways and these studies highlight the importance of multiple clearance routes in reducing the liability of a drug substance to be a victim of DDIs.

\section{OPINION AND FUTURE PERSPECTIVES}

\section{TDI Profiling}

Several important advances have been made in the implementation and design of TDI testing over recent years. These include: (1) the almost universal adoption of some sort of TDI testing programme within pharmaceutical companies and contract research organisations performing CYP inhibition studies, (2) the identification of a number of compounds which can be used as positive control substances for individual CYP TDI assays and (3) improvements in assay design (made possible by improved analytical sensitivity) to generate more accurate $\mathrm{K}_{\mathrm{I}}$ and $k_{\text {inact }}$ parameter estimates for use in in vitro-in vivo extrapolations. However, current TDI effect prediction methods are restricted by differences in TDI effects observed using different experimental systems (54), the complex interplay between inactivation and induction and uncertainty as to the actual rate of enzyme re-synthesis in man. Clinical studies are therefore still required to establish the true effect of a TDI positive substance in vivo.

\section{CYP IC 50 $_{5}$ Screening}

Most large pharmaceutical companies currently apply a combination of high and low throughput CYP inhibition screening methodologies to address the different needs of discovery and development projects. However, as the time costs of performing the necessary correlation work can be high (and the costs of misguided compound optimisation even higher), and with the decreasing costs associated with miniaturised assay formats, lower HLM concentrations and possibility to perform pooled sample analysis by LC-MS/MS, there is increasing use of human liver microsomal assays as the primary screening system. This allows a consistency of approach to be implemented and prevents chemical optimisation based upon data which may be different to that used in the final DDI risk assessment process.
Future perspectives for truly high-throughput MS/MS analysis remove the need for a chromatography step, the most time consuming part of the analysis process. Thermal or matrix-assisted laser desorption ionization (55) and direct sample injection technologies are examples of methods currently being developed.

\section{Investigation of DDI In Vivo Using Animal Models}

The science of in vivo DDI investigations using preclinical animal species has shown progress in recent years, with more studies being published describing drug treatment regimens and a growing number of recombinantly expressed non-human CYPs available for reaction phenotyping experiments. Although extrapolation of animal DDI study data to the human situation is fraught with complications (e.g. species differences in: substrate metabolism rates and routes, inhibitor selectivity, pharmacokinetics and tissue concentrations) use of animal data could help to de-risk the development of compounds where the in vitro human CYP data indicates a high risk of DDI, but where other factors may attenuate the impact of enzyme inhibition in vivo (56). Work has mainly been concentrated around CYP3A mediated metabolism in various species, making use of probe substrates and inhibitors such as midazolam and ketoconazole (56-58). However, although these substances are known to be highly CYP3A selective in man, the contribution of non-CYP3A enzymes to midazolam metabolism in the rat and the inhibition of multiple rat CYPs by ketoconazole encountered in a recent study by Mandlekar et al (59) exemplified the current difficulty in performing animal DDI studies from which clear conclusions for the human situation can be drawn. Future developments in this area are likely to come from a more detailed understanding of the enzymology of individual animal CYPs and progress in the development of "humanized" animals whose endogenous drug-metabolising enzymes have been genetically replaced with their human counterparts.

\section{Human In Vivo DDI Prediction}

Prospectively, there are always instances where in vivo human outcomes could not be fully appreciated from in vitro data. Retrospectively, however, in vitro systems are valuable tools to understand clinical DDIs. Cerivastatin, a potent HMGCoA reductase inhibitor, was thought to be at low risk of metabolism inhibition because the compound was metabolized by both CYP3A4 and CYP2C8; and the lack of clinically relevant interactions with commonly used drugs appeared to support this hypothesis (60). However, a significant interaction with gemfibrozil, and concerns over severe rhabdomyolysis associated with this type of interaction, led to its eventual withdrawl from the market $(61,62)$. Subsequent investigative studies indicated that gemfibrozil- $O$ glucuronide, a major metabolite of gemfibrozil, is an inhibitor of cerivastatin hepatic uptake transport via the organic anion transporter protein, as well as a mechanism-based inactivator of CYP2C8 $(63,64)$. Therefore, the impact of gemfibrozil on cerivastatin pharmacokinetics is likely to have been caused by a combination of hepatic uptake and CYP2C8 inhibition. This example clearly demonstrates the need to thoroughly exam- 
ine the roles of CYP-mediated metabolism in the context of other metabolic and transport processes involved in drug disposition.

Nevertheless, predictions of the likely interaction effect with competitive inhibitors based upon the in vitro CYP kinetics and $\mathrm{f}_{\mathrm{m}}$ calculations are reasonably well accepted. The current challenge is to simulate the time- and concentrationdependent effects of irreversible inactivators, quasi-irreversible inhibitors and inducer compounds on the pharmacokinetics of well established probe substrates. Various approaches can be taken to modelling DDIs, either using equations to predict the overall DDI magnitude or by modelling the inhibition effect with time over the period where exposure to both compounds is expected. Tools which have been applied range from homemade spreadsheets (65) to use of commercial pharmacokinetics and DDI modelling programs. Of these, the SimCYP software package provides the most sophisticated approach to simulation of clinical DDI studies, allowing substrate and inhibitor concentrations to be modelled over the time of a simulated clinical study in a population of virtual individuals, each with their own enzymatic and physiological status parameters, to give a population-based estimate of the DDI risk $(66,67)$. The inclusion of TDI and induction effects into the simulations offers the possibility to come even closer to the in vivo situation.

As with all modelling and simulation, the value of the predictions is directly dependent upon the quality and correct manipulation of the input data. High quality experimental practices and scientifically rigorous assessment will therefore remain a cornerstone of DDI avoidance and risk assessment.

\section{ACKNOWLEDGEMENT}

The work of Pascal Schenk, Vittorio Bona, Franz Bucheli and Katja Heinig (F. Hoffmann-La Roche, Basel, Switzerland) who generated the data used in the examples is gratefully acknowledged.

\section{REFERENCES}

1. A. D. Rodrigues (ed.). In Drug-Drug Interactions. Drugs and the Pharmaceutical Sciences, 116. Marcel Dekker, New York, 2002.

2. FDA. Guidance for Industry: Drug interaction studies-study design, data analysis and implications for dosing and labelling. Available at: http://www.fda.gov/cder/guidance/index.htm.

3. O. V. Trubetskoy, J. R. Gibson, and B. D. Marks. Highly miniaturized formats for in vitro drug metabolism assays using Vivid fluorescent substrates and recombinant human cytochrome P450 enzymes. J. Biomol. Screen. 10(1):56-66 (2005).

4. C. L. Crespi, V. P. Miller, and D. M. Stresser. Design and Application of Fluorogenic Assays for Human Cytochrome P450 Inhibition. In E. F. Johnson, and M. R. Waterman (eds.), Cytochrome P450, Part C. Vol 357, Academic Press, London, 2002.

5. J. J. Cali, D. Ma M. Sobol et al. Luminogenic cytochrome P450 assays. Expert Opin. Drug Metab. Toxicol. 2(4):629-645 (2006).

6. A. Di Marco, I. Marcucci M. Verdirame et al. Development and validation of a high-throughput radiometric CYP3A4/5 inhibition assay using tritiated testosterone. Drug Metab. Dispos. 33 (3):349-358 (2005)

7. A. Di Marco, A. Cellucci, A. Chaudhary, M. Fonsi, and R. Laufer. High-throughput radiometric CYP2C19 inhibition assay using tritiated (S)-mephenytoin. Drug Metab. Dispos. 35 (10):1737-1743 (2007).
8. G. C. Moody, S. J. Griffin, A. N. Mather, D. F. McGinnity, and R. J. Riley. Fully automated analysis of activities catalysed by the major human liver cytochrome P450 (CYP) enzymes: assessment of human CYP inhibition potential. Xenobiotica. 29(1):53-75 (1999).

9. R. L. Walsky, and R. S. Obach. Validated assays for human cytochrome P450 activities. Drug Metab. Dispos. 32(6):647-660 (2004).

10. R. Weaver, K. S. Graham, I. G. Beattie, and R. J. Riley. Cytochrome $\mathrm{P} 450$ inhibition using recombinant proteins and mass spectrometry/multiple reaction monitoring technology in a cassette incubation. Drug Metab. Dispos. 31(7):955-966 (2003).

11. E. A. Dierks, K. R. Stams, H. K. Lim, G. Cornelius, H. Zhang, and S. E. Ball. A method for the simultaneous evaluation of the activities of seven major human drug-metabolizing cytochrome P450s using an in vitro cocktail of probe substrates and fast gradient liquid chromatography tandem mass spectrometry. Drug Metab. Dispos. 29(1):23-29 (2001).

12. R. L. Walsky, A. V. Astuccio, and R. S. Obach. Evaluation of 227 drugs for in vitro inhibition of cytochrome P450 2B6. J. Clin. Pharmacol. 46(12):1426-1438 (2006).

13. R. L. Walsky, E. A. Gaman, and R. S. Obach. Examination of 209 drugs for inhibition of cytochrome P450 2C8. J. Clin. Pharmacol. 45(1):68-78 (2005).

14. M. Shou. Kinetic Analysis for Multiple Substrate Interaction at the Active Site of Cytochrome P450. In E. F. Johnson, and M. R Waterman (eds.), Cytochrome P450 Part C. Vol 357, 1st edn, Academic Press, New York, 2002, pp. 261-276.

15. M. Shou, Y. Lin P. Lu et al. Enzyme kinetics of cytochrome P450 mediated reactions. Current Drug Metabolism. 2(1):17-36 (2001).

16. J. B. Houston, and A. Galetin. Modelling atypical CYP3A4 kinetics: Principles and pragmatism. Arch. Biochem. Biophys. 433(2):351-360 (2005).

17. J. B. Houston, and K. E. Kenworthy. In vitro-in vivo scaling of cyp kinetic data not consistent with the classical MichaelisMenten model. Drug Metab. Dispos. 28(3):246-254 (2000).

18. J. M. Hutzler, and T. S. Tracy. Atypical kinetic profiles in drug metabolism reactions. Drug Metab. Dispos. 30(4):355-362 (2002).

19. W. M. Atkins. Current views on the fundamental mechanisms of cytochrome P450 allosterism. Expert Opin. Drug Metab. Toxicol. 2(4):573-579 (2006).

20. W. F. Busby, J. M. Ackermann, and C. L. Crespi. Effect of methanol, ethanol, dimethyl sulfoxide, and acetonitrile on in vitro activities of cDNA-expressed human cytochromes P-450. Drug Metab. Dispos. 27(2):246-249 (1999)

21. R. Vuppugalla, S. Y. Chang, H. Zhang, P. H. Marathe, and D. A. Rodrigues. Effect of commonly used organic solvents on the kinetics of cytochrome P450 2B6- and 2C8-dependent activity in human liver microsomes. Drug Metab. Dispos. 35(11):1990-1995 (2007).

22. R. P. Austin, P. Barton, S. L. Cockroft, M. C. Wenlock, and R. J. Riley. The influence of nonspecific microsomal binding on apparent intrinsic clearance, and its prediction from physicochemical properties. Drug Metab. Dispos. 30(12):1497-1503 (2002).

23. D. Hallifax, and J. B. Houston. Binding of drugs to hepatic microsomes: Comment and assessment of current prediction methodology with recommendation for improvement (1). Drug Metab. Dispos. 34(4):724-726 (2006).

24. L. Di, E. H. Kerns, S. Q. Li, and G. T. Carter. Comparison of cytochrome $\mathrm{P} 450$ inhibition assays for drug discovery using human liver microsomes with LC-MS, rhCYP450 isozymes with fluorescence, and double cocktail with LC-MS. Int. J. Pharm. 335 (1-2):1-11 (2007).

25. F. Gao, D. L. Johnson S. Ekins et al. Optimizing higher throughput methods to assess drug-drug interactions for CYP1A2, CYP2C9, CYP2C19, CYP2D6, rCYP2D6, and CYP3A4 in vitro using a single point IC(50). J. Biomol. Screen. 7(4):373-382 (2002).

26. J. B. Houston, K. E. Kenworthy, and A. Galetin. Typical and atypical kinetics. In J. S. Lee, R. S. Obach, and M. B. Fisher (eds.), Drug Metabolising Enzymes, Marcel Dekker, New York, 2002, pp. 211-254.

27. R. B. Silverman. Mechanism-based Enzyme Inactivation: Chemistry and Enzymology. Vol 1, CRC Press, Boca Raton, 1988. 
28. B. Ma, T. Prueksaritanont, and J. H. Lin. Drug interactions with calcium channel blockers: Possible involvement of metaboliteintermediate complexation with CYP3A. Drug Metab. Dispos. 28 (2):125-130 (2000).

29. X. J. Zhao, D. R. Jones, Y.-H. Wang, S. W. Grimm, and S. D. Hall. Reversible and irreversible inhibition of CYP3A enzymes by tamoxifen and metabolites. Xenobiotica. 32(10):863-878 (2002).

30. S. Zhou, S. Y. Chan B. C. Goh et al. Mechanism-based inhibition of cytochrome P450 3A4 by therapeutic drugs. Clin. Pharmacokinet. 44(3):279-304 (2005).

31. A. S. Kalgutkar, R. S. Obach, and T. S. Maurer. Mechanismbased inactivation of cytochrome P450 enzymes: Chemical mechanisms, structure-activity relationships and relationship to clinical drug-drug interactions and idiosyncratic adverse drug reactions. Current Drug Metabolism. 8(5):407-447 (2007).

32. F. P. Guengerich. Cytochrome P450 oxidations in the generation of reactive electrophiles: epoxidation and related reactions. Arch. Biochem. Biophys. 409:59-71 (2003).

33. R. S. Obach, R. L. Walsky, and K. Venkatakrishnan. Mechanismbased inactivation of human cytochrome P450 enzymes and the prediction of drug-drug interactions. Drug Metab. Dispos. 35 (2):246-255 (2007).

34. D. A. Fairman, C. Collins, and S. Chapple. Progress curve analysis of CYP1A2 inhibition: A more informative approach to the assessment of mechanism-based inactivation? Drug Metab. Dispos. 35(12):2159-2165 (2007).

35. R. B. Silverman. Mechanism-based enzyme inactivators. In D. L. Purich (ed.), Enzyme Kinetics and Mechanism. Part D: Developments in Enzyme Dynamics. Vol 249, Academic Press, New York, 1995, pp. 240-283.

36. F. Ghanbari, K. Rowland-Yeo J. C. Bloomer et al. A critical evaluation of the experimental design of studies of mechanism based enzyme inhibition, with implications for in vitro-in vivo extrapolation. Current Drug Metabolism. 7(3):315-334 (2006).

37. R. L. Walsky, R. S. Obach, E. A. Gaman, J. P. R. Gleeson, and W. R. Proctor. Selective inhibition of humam cytochrome P4502C8 by montelukast. Drug Metab. Dispos. 33(3):413-418 (2005).

38. K. E. Kenworthy, J. C. Bloomer, S. E. Clarke, and J. B. Houston. CYP3A4 drug interactions: Correlation of 10 in vitro probe substrates. BJCP, Br. J. Clin. Pharmacol. 48(5):716-727 (1999).

39. J. K. Yano, M. R. Wester, G. A. Schoch, K. J. Griffin, C. D. Stout, and E. F. Johnson. The structure of human microsomal cytochrome P450 3A4 determined by X-ray crystallography to 2.05-A resolution. J. Biol. Chem. 279(37):38091-38094 (2004).

40. K. K. Chohan, S. W. Paine, and N. J. Waters. Quantitative structure activity relationships in drug metabolism. Current Topics in Medicinal Chemistry. 6(15):1569-1578 (2006).

41. R. Arimoto. Computational models for predicting interactions with cytochrome p450 enzyme. Current Topics in Medicinal Chemistry. 6(15):1609-1618 (2006).

42. D. A. Smith, M. J. Ackland, and B. C. Jones. Properties of cytochrome P450 isoenzymes and their substrates. Part 2: Properties of cytochrome P450 substrates. Drug Discov. Today. 2(11):479-486 (1997)

43. M. Rowland, and T. N. Tozer. Clinical Pharmacokinetics: Concepts and Applications, 3rd edn, Lippincott Williams and Wilkins, Philadelphia, 1995.

44. R. S. Obach, R. L. Walsky, K. Venkatakrishnan, E. A. Gaman, J. B. Houston, and L. M. Tremaine. The utility of in vitro cytochrome P450 inhibition data in the prediction of drug-drug interactions. $J$. Pharmacol. Exp. Ther. 316(1):336-348 (2006).

45. A. Galetin, H. Burt, L. Gibbons, and J. B. Houston. Prediction of time-dependent CYP3A4 drug-drug interactions: Impact of enzyme degradation, parallel elimination pathways, and intestinal inhibition. Drug Metab. Dispos. 34(1):166-175 (2006).

46. C. Lu, G. T. Miwa, R. P. Shimoga, L. S. Gan, and S. K. Balani. A novel method for the prediction of drug-drug interactions in humans based on in vitro cytochrome P450 phenotypic data. Drug Metab. Dispos. 35(1):79-85 (2007).

47. K. Ito, T. Iwatsubo, S. Kanamitsu, K. Ueda, H. Suzuki, and Y. Sugiyama. Prediction of pharmacokinetic alterations caused by drug-drug interactions: Metabolic interaction in the liver. Pharmacol. Rev. 50(3):387-411 (1998).
48. J. Y. Chien, A. Lucksiri, I. C. S. Ernest, J. C. Gorski, S. A. Wrighton, and S. D. Hall. Stochastic prediction of CYP3Amediated inhibition of midazolam clearance by ketoconazole. Drug Metab. Dispos. 34(7):1208-1219 (2006).

49. K. Ito, H. S. Brown, and J. B. Houston. Database analyses for the prediction of in vivo drug-drug interactions from in vitro data. Br. J. Clin. Pharmacol. 57(4):473-486 (2004).

50. S. I. Kanamitsu, K. Ito, and Y. Sugiyama. Quantitative prediction of in vivo drug-Drug interactions from in vitro data based on physiological pharmacokinetics: Use of maximum unbound concentration of inhibitor at the inlet to the liver. Pharm. Res. 17(3):336-343 (2000).

51. H. S. Brown, K. Ito, A. Galetin, and J. B. Houston. Prediction of in vivo drug-drug interactions from in vitro data: Impact of incorporating parallel pathways of drug elimination and inhibitor absorption rate constant. Br. J. Clin. Pharmacol. 60(5):508-518 (2005).

52. Y.-H. Wang, D. R. Jones, and S. D. Hall. Prediction of cytochrome P450 3A inhibition by verapamil enantiomers and their metabolites. Drug Metab. Dispos. 32(2):259-266 (2004).

53. K. Ito, D. Hallifax, R. S. Obach, and J. B. Houston. Impact of parallel pathways of drug elimination and multiple cytochrome P450 involvement on drug-drug interactions: CYP2D6 paradigm. Drug Metab. Dispos. 33(6):837-844 (2005).

54. T. M. Polasek, and J. O. Miners. In vitro approaches to investigate mechanism-based inactivation of CYP enzymes. Expert Opin. Drug Metab. Toxicol. 3(3):321-329 (2007).

55. J. Wu, C. S. Hughes P. Picard et al. High-throughput cytochrome P450 inhibition assays using laser diode thermal desorptionatmospheric pressure chemical ionization-tandem mass spectrometry. Anal. Chem. 79(12):4657-4665 (2007).

56. P. H. Marathe, and A. D. Rodrigues. In vivo animal models for investigating potential CYP3A- and Pgp- mediated drug-drug interactions. Current Drug Metabolism. 7(7):687-704 (2006).

57. T. Kanazu, Y. Yamaguchi, N. Okamura, T. Baba, and M. Koike. Model for the drug-drug interaction responsible for CYP3A enzyme inhibition. II: Establishment and evaluation of dexamethasonepretreated female rats. Xenobiotica. 34(5):403-413 (2004).

58. S. N. Umathe, P. V. Dixit, V. kumar, K.U. Bansod, and M. M. Wanjari. Quercetin pretreatment increases the bioavailability of pioglitazone in rats: Involvement of CYP3A inhibition. Biochem. Pharmacol. 75(8):1670-1676 (2008).

59. S. V. Mandlekar, A. V. Rose G. Cornelius et al. Development of an in vivo rat screen model to predict pharmacokinetic interactions of CYP3A4 substrates. Xenobiotica. 37(9):923-942 (2007).

60. W. Muck. Clinical pharmacokinetics of cerivastatin. Clin. Pharmacokinet. 39(2):99-116 (2000).

61. B. Roca, B. Calvo, and R. Monferrer. Severe rhabdomyolysis and cerivastafin-gemfibrozil combination therapy (2). Ann. Pharmacother. 36(4):730-731 (2002).

62. J.T. Backman, C. Kyrklund, M. Neuvonen, and P. J. Neuvonen. Gemfibrozil greatly increases plasma concentrations of cerivastatin. Clin. Pharmacol. Ther. 72(6):685-691 (2002).

63. B. W. Ogilvie, D. Zhang W. Li et al. Glucuronidation converts gemfibrozil to a potent, metabolism-dependent inhibitor of CYP2C8: Implications for drug-drug interactions. Drug Metab. Dispos. 34(1):191-197 (2006).

64. Y. Shitara, M. Hirano, H. Sato, and Y. Sugiyama. Gemfibrozil and its glucoronide inhibit the organic anion transporting polypeptide 2 (OATP2/OATP1B1:SLC21A6)-mediated hepatic uptake and CYP2C8-mediated metabolism of cerivastatin: Analysis of the mechanism of the clinically relevant drug-drug interaction between cerivastatin and gemfibrozil. J. Pharmacol. Exp. Ther. 311 (1):228-236 (2004).

65. R. J. Riley, K. Grime, and R. Weaver. Time-dependent CYP inhibition. Expert Opin. Drug Metab. Toxicol. 3(1):51-66 (2007).

66. E. M. Howgate, K. Rowland-Yeo, N. J. Proctor, G. T. Tucker, and A. Rostami-Hodjegan. Prediction of in vivo drug clearance from in vitro data. I: Impact of inter-individual variability. Xenobiotica. 36(6):473-497 (2006).

67. A. Rostami-Hodjegan, and G. Tucker. 'In silico' simulations to assess the 'in vivo' consequences of 'in vitro' metabolic drug-drug interactions. Drug Discov. Today: Technol. 1(4):441-448 (2004). 